\section{Pacific Northwest}

National Laboratory

Operated by Battelle for the

U.S. Department of Energy

\section{Review of the Technical Basis of the Hydrogen Control Limit for Operations in Hanford Tank Farms}

L.A. Mahoney

C.W. Stewart

November 2002

Prepared for the U.S. Department of Energy under Contract DE-AC06-76RL01830 


\section{DISCLAIMER}

This report was prepared as an account of work sponsored by an agency of the United States Government. Neither the United States Government nor any agency thereof, nor Battelle Memorial Institute nor any of their employees makes any warranty, express or implied, or assumes any legal liability or responsibility for the accuracy, completeness, or usefulness of any information, apparatus, product, or process disclosed or represents that its use would not infringe privately owned rights. Reference herein to any specific commercial product, process, or service by trade name, trademark, manufacturer, or otherwise does not necessarily constitute or imply its endorsement, recommendation, or favoring by the United States Government or any agency thereof, or Battelle Memorial Institute. The views and opinions of authors expressed herein do not necessarily state or reflect those of the United States Government or any agency thereof.

\section{PACIFIC NORTHWEST NATIONAL LABORATORY operated by \\ BATTELLE \\ for the \\ UNITED STATES DEPARTMENT OF ENERGY under Contract DE-AC06-76RL01830}

Printed in the United States of America

Available to DOE and DOE contractors from the Office of Scientific and Technical Information,

P.O. Box 62, Oak Ridge, TN 37831-0062;

ph: (865) 576-8401

fax: (865) 576-5728

email: reports@adonis.osti.gov

Available to the public from the National Technical Information Service,

U.S. Department of Commerce, 5285 Port Royal Rd., Springfield, VA 22161

ph: (800) 553-6847

fax: (703) 605-6900

email: orders@ntis.fedworld.gov

online ordering: http://www.ntis.gov/ordering.htm

This document was printed on recycled paper. 


\title{
Review of the Technical Basis of the Hydrogen Control Limit for Operations in Hanford Tank Farms
}

\author{
LA Mahoney \\ CW Stewart
}

November 2002

Prepared for

the U.S. Department of Energy

under contract DE-AC06-76RLO 1830

Pacific Northwest National Laboratory

Richland, WA 99352 


\begin{abstract}
The radioactive waste in Hanford tanks generates a flammable gas mixture and releases it into the tank headspace. The potential hazard resulting from flammable gas generation requires that controls be established to prevent ignition and halt operations if gas concentrations reach levels of concern. A control limit of 6,250 ppm hydrogen has been in use at Hanford for several years when only hydrogen is monitored. The hydrogen-based control limit is intended to conservatively represent $25 \%$ of the lower flammability limit of a gas mixture, accounting for the presence of flammable gases other than hydrogen, with ammonia being the primary concern. This report reviews the technical basis of the current control limit based on observed and projected concentrations of hydrogen and ammonia representing a range of gas release scenarios. The conclusion supports the continued use of the current 6,250-ppm hydrogen control limit.
\end{abstract}




\section{Summary}

The radioactive waste in Hanford tanks generates flammable gases. Hydrogen and ammonia contribute significantly to the flammability of the gas mixture. Steady-state and spontaneous gas releases during waste storage, and operations that disturb the waste and induce gas releases, must be controlled to prevent ignition of flammable gas concentrations in a tank headspace or other volume that could potentially release radioactive or toxic material in a deflagration.

The tank farms at Hanford are operated under an approved Authorization Basis that requires adequate ventilation to control steady-state background releases, controls ignition sources when and where flammable gases may be present, and requires monitoring of flammable gas concentrations during specific operations and conditions in tank farms. A limit of $25 \%$ of the lower flammability limit (LFL) has been established as the control.

A hydrogen concentration of $6,250 \mathrm{ppm}$ is specified to represent $25 \%$ of the LFL of the gas mixture when only hydrogen is measured. This control limit is quite conservative and, on the basis of retained gas composition measurements and observations from gas monitoring and vapor sampling, a control limit of 7,500, 8,000, or even 9,000 ppm hydrogen could adequately represent $25 \%$ of the LFL in most tanks.

This report examines the existing data and experience with flammability measurements in Hanford radioactive waste tanks to evaluate the technical basis for the existing 6,250-ppm hydrogen control limit and to determine whether any change is warranted. The preponderance of evidence supports continued use of the current control limit.

Though a large majority of the data and observations show that a higher hydrogen control limit could be used to represent $25 \%$ of the mixture LFL, there are a few cases in which the current control limit is only just adequate or even slightly nonconservative. Flammable gas concentrations predicted by theoretical models and measures during several historical operations in Hanford waste storage tanks have been examined. Several of these observations have also been extrapolated to the limits of the observed "population" of hydrogen inventories and ammonia equilibrium partial pressures based on the available measurements. The results are summarized as follows:

- Analyses of background or steady-state gas release with barometric breathing indicated that the $6,250 \mathrm{ppm}$ hydrogen control limit provided an adequate or conservative representation of $25 \%$ of the mixture LFL in almost $95 \%$ of all single-shell and doubleshell tanks.

- In events dominated by bubble release, such as buoyant displacement gas release events and bubble slurry flows in SY-101 and saltwell pumping in S-106 and A-101, the existing control limit of 6,250 ppm hydrogen is conservative, and a higher control limit of 7,000 to 8,000 ppm hydrogen could be supported.

- In operations that involve enhanced evaporation of ammonia, such as SY-101 waste transfer into SY-102, the physical upper limit on the ammonia concentration prevents achieving flammability. However, the data do not support any flammability control limit 
expressed only in terms of hydrogen. There is no mechanism for significant hydrogen release during transfer, and it is very unlikely for the hydrogen concentration to approach the limit in the first place.

- In operations that involve significant passive evaporation of ammonia, typified by U-105 saltwell pumping, ammonia concentrations can be expected to remain below $36,000 \mathrm{ppm}$ ammonia. With 6,250 ppm hydrogen the mixture would be less than $40 \%$ of the LFL but greater than $25 \%$ of the LFL, which does not support a control limit higher than the current level.

In summary, the available measurements, analysis results, and observations of historical gas releases show that:

- The 6,250-ppm hydrogen control limit is very conservative with respect to $25 \%$ of the actual LFL in the majority of conditions and tanks.

- In some cases, where ammonia evaporation is significant, a mixture containing $6,250 \mathrm{ppm}$ hydrogen can exceed $25 \%$ of LFL but cannot approach $100 \%$ of LFL even when extrapolated to the highest measured ammonia concentrations.

- Because of these facts, there is no sound technical basis to recommend a higher hydrogen control limit.

Based on these conclusions, we recommend that the current 6,250-ppm hydrogen control limit continue to be used for operations in Hanford tank farms. 


\section{Contents}

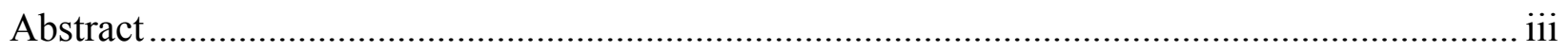

Summary

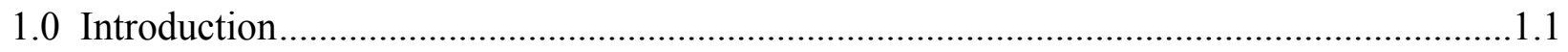

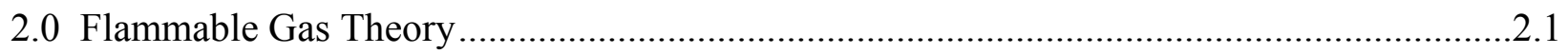

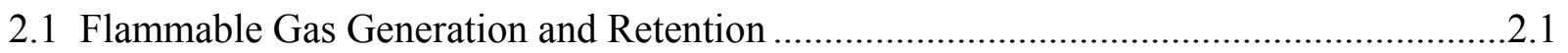

2.2 Release Mechanisms for Poorly Soluble and Soluble Gases............................................... 2.1

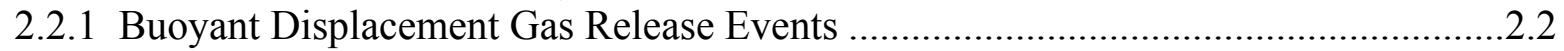

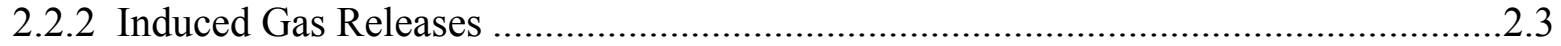

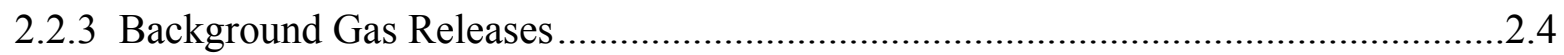

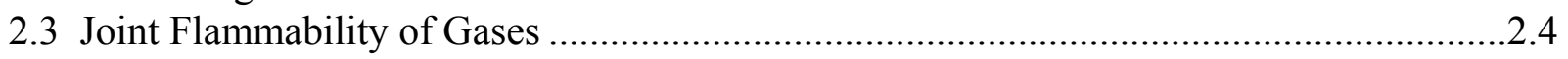

2.4 Effect of Water Vapor on Ammonia Flammability .............................................................



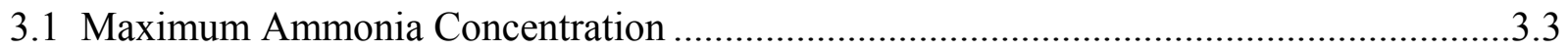

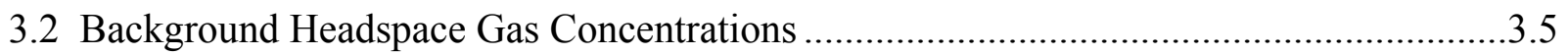

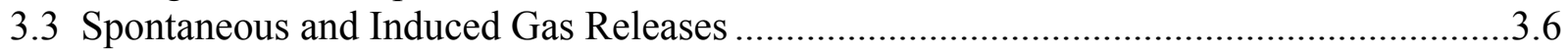

3.3.1 SY-101 Spontaneous Gas Releases ......................................................................



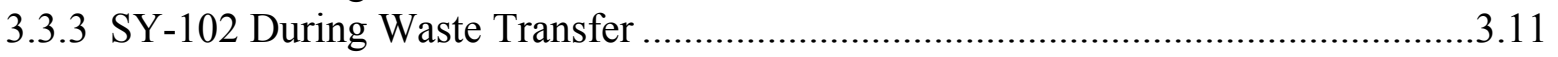

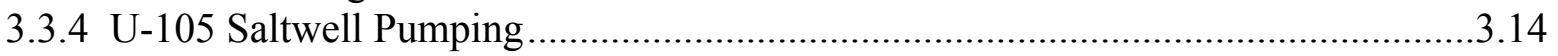

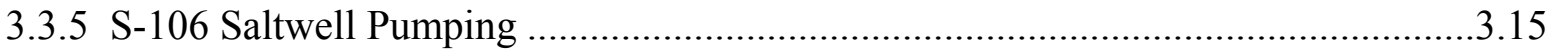

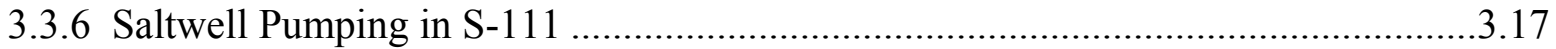

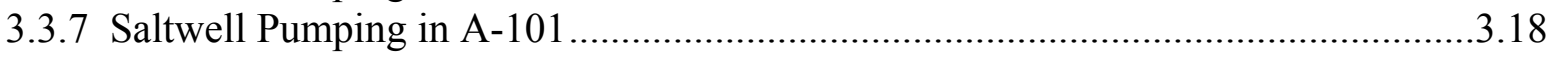

3.4 Theoretical Modeling of Ammonia Releases ………………........................................19

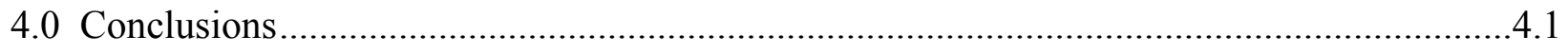

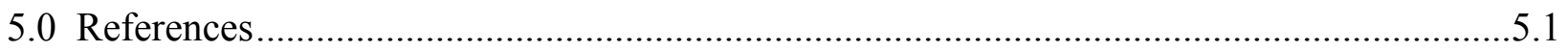




\section{Figures}

3.1 Mixture Flammability with 6,250 ppm Hydrogen ................................................... 3.2

3.2 Hydrogen Concentration for 100\% and 25\% LFL Versus Ammonia Concentration......... 3.2

3.3 Distribution of Fraction of LFL with $\left[\mathrm{H}_{2}\right]=6,250 \mathrm{ppm}$ for Barometric Breathing .......... 3.6

3.4 Hydrogen and Ammonia in SY-101 During the June 26, 1993 BDGRE ....................... 3.8

3.5 Hydrogen and Ammonia in SY-101 During the August 27, 1993 BDGRE ................... 3.9

3.6 Hydrogen and Ammonia in SY-101 During Second Waste Transfer and Dilution ......... 3.10

3.7 Hydrogen and Ammonia in SY-102 During First Transfer from SY-101 .................... 3.12

3.8 Hydrogen and Ammonia in SY-102 During Third Waste Transfer ............................. 3.12

3.9 Hydrogen and Ammonia in U-105 During Saltwell Pumping..................................... 3.14

3.10 Hydrogen and Ammonia in S-106 During Early Saltwell Pumping............................. 3.16

3.11 Hydrogen Concentration During Saltwell Pumping in S-111 .................................... 3.17

3.12 Hydrogen and Ammonia in A-101 During Saltwell Pumping...................................... 3.18

\section{Tables}

2.1 Effect of Water Vapor on Ammonia Ignition .......................................................... 2.6

3.1 Ammonia Concentration in Liquid and Equilibrium Gas Concentration .......................... 3.3

3.2 Dissolved Ammonia Concentration in Liquid ........................................................ 3.5 


\subsection{Introduction}

The radioactive waste in Hanford tanks generates flammable gases. The primary flammable gas generated in the Hanford wastes is hydrogen; additional fuel gases of potential concern are ammonia, methane, and other hydrocarbons. The flammability of a gas mixture depends on the concentration of each of the component gases with respect to its own flammability limit as a pure gas. Extensive measurements and laboratory testing have shown that only hydrogen and ammonia contribute significantly to the flammability of the gases generated, retained, and released by Hanford radioactive wastes (Mahoney et al. 2000a).

In most tanks, the gas mixture generated in the waste is released directly into the headspace, where it is diluted by ventilation. Many tanks, however, have retained a significant volume of gas, and several of them periodically release some of the stored gas into the tank headspace. Various operations such as waste transfer and retrieval, saltwell pumping, or mixer pump operation disturb the waste and induce gas releases. These operations must be controlled to prevent ignition of flammable gas concentrations in a tank headspace or other volume that could potentially release radioactive or toxic material in a deflagration.

The tank farms at Hanford are being operated under an approved Authorization Basis that consists of the Final Safety Analysis Report (FSAR) (CHG 2002a), which evaluates a range of potentially hazardous scenarios, and the Technical Safety Requirements (TSR) (CHG 2000b), which documents the controls that have been established to mitigate the hazards (Johnson et al. 2001). The accidents covered by the FSAR involve accumulation or presence of flammable gas in a volume such that credible ignition sources typical in tank farms can cause the gas to burn, including the following:

- Accumulation of steady-state, or background, gas releases in poorly ventilated tank headspaces, pits, risers, and connected air spaces, and waste intrusive equipment.

- Release of gas accumulated within the waste matrix by natural spontaneous mechanisms such as buoyant instability or induced by waste disturbance.

The TSR includes requirements to ensure ventilation systems (active and passive) are operable and adequate to control background releases and ignition sources when and where flammable gases may be present and to monitor flammable gas concentrations during specific operations and conditions in tank farms. CHG has adopted the National Fire Protection Association (NFPA 1969) recommendation of using $25 \%$ of the LFL as the point at which operational restrictions and additional ignition controls are imposed. Monitoring results in excess of $25 \%$ of the LFL result in actions that

- Prevent manned work and use of unqualified equipment in an area when and where flammable gas concentrations exceed the control limit.

- Prevent continued manned work and use of potentially unqualified equipment and materials if flammable gas concentrations rise above the control limit during manned work activities.

- Halt waste-disturbing activities if flammable gas concentrations exceed the control limit. 
These functions are typically monitored using hand-held combustible-gas monitors (CGM) that provide a direct reading of the local gas flammability as a percentage of the LFL. In this case, the control limit is set at $25 \%$ of the LFL as measured by the CGM. This measurement theoretically includes the contribution of all the component fuel gases. In a number of tanks, installed standard hydrogen monitoring systems (SHMS) are used that measure only hydrogen. This requires a control limit for hydrogen alone that conservatively accounts for the contribution of the other fuel gases not measured and results in a somewhat reduced hydrogen concentration compared with that of pure hydrogen.

A hydrogen concentration of $6,250 \mathrm{ppm}$ is specified in the FSAR to represent $25 \%$ of the LFL of the gas mixture when only hydrogen is measured. This limit is $25 \%$ of hydrogen concentration of a mixture containing 2.5 vol\% hydrogen and 2 vol $\%$ ammonia. This mixture would be just flammable (100\% LFL) on the conservative assumptions that the LFLs for pure hydrogen and ammonia were, respectively, 3.5 vol\% (35,000 ppm) and 8 vol\% (80,000 ppm). These are the LFLs that were assumed in an earlier document (Estey 1998).

The control limit of 6,250 ppm hydrogen is quite conservative because pure hydrogen in air actually has an LFL of 4 vol\% (40,000 ppm), and pure ammonia in air has an LFL of $15 \mathrm{vol} \%$ $(150,000 \mathrm{ppm})$ (Mahoney et al. 2000a). A control limit set at $25 \%$ of LFL, if hydrogen were the dominant flammable gas, would be close to $10,000 \mathrm{ppm}$. On the basis of retained gas composition measurements and observations from gas monitoring and vapor sampling, it has been suggested that a control limit of 7,500, 8,000, or even 9,000 ppm hydrogen could adequately represent $25 \%$ of the LFL.

This report examines the existing theory, data, and experience with flammability measurements in Hanford radioactive waste tanks to evaluate the technical basis for the existing 6,250-ppm hydrogen control limit and to determine whether any change is warranted. The preponderance of evidence supports continued use of the current control limit.

Section 2 summarizes the theory developed over the past 10 years on flammable gas generation, retention, and release and the flammability of gas mixtures. The conclusion is that hydrogen and ammonia are the two flammable gases of concern. Section 3 treats specific issues and operations in detail beginning with data on the maximum possible ammonia concentration followed by discussions of spontaneous and induced gas releases, including buoyant displacements in SY-101, transfers from SY-101 to SY-102, and saltwell pumping in several tanks. The evidence presented in Section 3 shows that it is possible in transfers and saltwell pumping to exceed $25 \%$ of the LFL with a hydrogen concentration of $6,250 \mathrm{ppm}$ but not possible to reach the LFL. Section 4 summarizes the conclusions, and Section 5 lists references. 


\subsection{Flammable Gas Theory}

The theoretical basis for estimating the composition of a released gas mixture and calculating its flammability is given in this section. Section 2.1 summarizes gas generation and retention in Hanford wastes, and Section 2.2 gives a brief description of the different mechanisms by which gases are released. Section 2.3 discusses the calculation of gas mixture flammability.

\subsection{Flammable Gas Generation and Retention}

Hydrogen, nitrogen, nitrous oxide, ammonia, methane, and other organic compounds are found in the headspaces of waste tanks and in the liquid and solid wastes (Johnson et al. 2001; Mahoney et al. 1999) they contain. Hydrogen is formed in Hanford waste in three distinct ways: from radiolysis of water, during the cascade of radiolytic and chemical oxidation reactions of the organic compounds, and during the corrosion of the steel tank walls (Stock 2000). The corrosion contribution is generally negligible and the organic decomposition portion typically greater than that of water radiolysis. Ammonia arises in part from the oxidation reactions of the nitrogencontaining complexants and by the hydrolysis of nitriles and amides that are produced during oxidation of other organic compounds. Nitrogen and nitrous oxide, as well as methane and other hydrocarbons, are produced along with ammonia during the complex degradation sequences of the complexants and other organics.

Because most of the flammable gases, particularly hydrogen, are not very soluble in the waste, they readily come out of solution to form discrete bubbles. In liquid waste, the bubbles rise to the surface and deposit their gas directly into the headspace. The bubbles that form in the liquid-solid sediment are held by the surrounding particles and continue to grow in place. Bubbles may be trapped in the pore spaces between particles if the particles are relatively large or if the lithostatic load holding the particles in contact is high (Gauglitz et al. 1996). If the particles are small or the lithostatic load is low, the bubbles push the particles apart and become discrete "round" bubbles. In either case, the gas in the bubbles assumes a composition determined by the equilibrium vapor pressure of each gas as it exists in solution.

Ammonia is extremely soluble, and the bulk of it remains in solution; however, it also occupies any bubbles present in concentration proportional to its vapor pressure. It also evaporates freely from any liquid waste surface exposed to the headspace atmosphere. Nitrous oxide has a solubility that falls between that of ammonia and hydrogen, and its behavior shows similarities to both. Nitrogen and the minor gases generally follow the behavior of hydrogen.

\subsection{Release Mechanisms for Poorly Soluble and Soluble Gases}

Considerable attention has been devoted to the mechanisms that produce waste gas releases and the release rate and quantity of gases released (Stewart et al. 1996; Meyer et al. 1997; Meyer and Stewart 2001; Johnson et al. 2001). For this work, two waste gas release mechanisms are considered: bubble release and evaporation. Both mechanisms occur simultaneously; the waste composition and release conditions determine which process dominates. 
Gas releases may also be divided into three types: background, or steady-state release; induced releases; and spontaneous release events. Background releases occur more or less continuously by both bubble detachment and evaporation at varying rates in all tanks, generally in proportion to the gas generation rate in the waste. ${ }^{\text {(a) }}$ Background release rates are low and are diluted to insignificance by passive ventilation in all but a few tanks that have very high gas generation rates ( $\mathrm{Hu}$ et al. 2002). Induced releases are caused by a disturbance to the waste such as mixing, saltwell pumping, retrieval, and waste transfer. Induced releases can be controlled to some extent by halting or moderating the disturbance. This kind of waste disturbance may favor bubble or evaporative gas releases. Spontaneous releases have been observed in many tanks (McCain 2001) but are typically insignificant, representing only temporary elevations in the background gas release rate. Only buoyant displacement gas release events (BDGREs) that occur in some double-shell tanks (DSTs) have resulted in hydrogen concentrations exceeding $25 \%$ of the LFL (Hedengren et al. 2000a). ${ }^{(b)}$

The relationship of evaporative and bubble release mechanisms is discussed for each release type in the following sections. Section 2.2.1 focuses on BDGREs, Section 2.2.2 summarizes important kinds of induced releases, and Section 2.2.3 discusses background gas release.

\subsubsection{Buoyant Displacement Gas Release Events}

The BDGREs that have occurred in Tanks SY-103, AW-101, AN-103, AN-104, and AN-105 and in $\mathrm{SY}-101^{\mathrm{c})}$ prior to mixing in late 1993 are primarily bubble releases. Bubbles trapped in the sediment grow until the sediment becomes buoyant with respect to the liquid above. At that point, large portions of sediment break free and rise to the surface, where they disintegrate and release a fraction of their gas to the headspace. These releases are relatively rapid (several minutes to several hours) and have produced the highest headspace hydrogen concentrations measured to date.

Evaporative ammonia releases during BDGREs are small to negligible despite the temporary surface agitation during the event. The rapid upwelling of bubbles is also accompanied by entrained liquid containing dissolved ammonia. However, these tanks all have a floating crust layer that effectively limits evaporation as the liquid drains back through it. Most of the ammonia is released with the bubbles, and the measured hydrogen/ammonia ratios in the headspace during BDGREs are similar to those of retained gas. Ammonia evaporation is not a large contribution. Two large BDGREs from SY-101 are described in detail in Section 4.

BDGREs can also be induced by supernate retrieval or mixer pump operation (Wells et al. 2002). However, they exhibit essentially the same behavior (e.g., gob size, gas release volume, time period, etc.) as those occurring spontaneously.

(a) Background releases are observed to vary continuously with seasonal temperature changes and other effects (see Section 3.2). The term steady-state is not entirely correct; background is preferred.

(b) Severe seismic events could also release a large fraction of the gas bubble inventory but are not considered here because of their low frequency (Johnson et al. 2001).

(c) The 241- prefix for tank identifiers is not used in this report. 


\subsubsection{Induced Gas Releases}

Stewart et al. (2002) have evaluated the gas release behavior of nine authorized global wastedisturbing activities in Hanford waste storage tanks: waste removal from DSTs, waste addition to DSTs, saltwell pumping from single-shell tanks (SSTs), saltcake dissolution in and pumping from SSTs, water addition to DSTs or SSTs, mixer pump operation in DSTs, airlift circulator operation in DSTs, chemical addition in DSTs, and evaporation of water from supernatant liquid in DSTs. Gas release mechanisms occurring in these activities that have been observed to cause significant releases are summarized here.

Several types of waste disturbances can produce significant bubble releases, including mixer pump operation and saltwell pumping. As mentioned above, mixer pump operation and liquid retrieval can also induce BDGREs that are also dominated by bubble release. With the exception of saltwell pumping, these disturbances do not tend to produce significant concurrent evaporation of ammonia. Mixing mostly affects the waste near the tank bottom and does not appear to disturb the surface sufficiently to significantly enhance evaporation, as was observed during intense mixing of SY-101 after dilution in March 2000.

Evaporative releases favor liquid surfaces and a high concentration of dissolved ammonia in the liquid. If a liquid surface is stirred or agitated, the evaporative mass-transfer rate can be greatly increased. Transferring liquid waste into a tank is the primary waste disturbance that creates and/or stirs a liquid surface to increase evaporation. Gas releases resulting from transfers of SY-101 waste into SY-102 created the highest ammonia concentrations recorded by gas monitoring equipment. These events are described in Section 3.3.3.

The maximum possible ammonia concentration in the headspace resulting from an evaporative release corresponds to a partial pressure equal to the equilibrium vapor pressure of the dissolved ammonia. This bounding concentration is virtually impossible to achieve without continuous, vigorous mixing in the absence of ventilation. Otherwise, depletion of the surface inventory of dissolved gas by evaporation and finite mass transfer rates reduces the maximum practical headspace ammonia concentration to a fraction of the potential equilibrium value. To date, the ammonia concentrations measured in headspaces have been substantially lower than equilibrium values, and retained gas sampler (RGS) measurements show that the equilibrium ammonia concentrations would not be sufficient to reach the LFL in the presence of $6,250 \mathrm{ppm}$ hydrogen.

Saltwell pumping causes slow releases from both bubbles and evaporation. Evaporation occurs from the unsaturated but still moist, porous waste remaining after the drainable interstitial liquid has been removed. Some bubbles are released promptly through expansion when the liquid above them is removed and the hydrostatic pressure reduced. Others are not released until liquid drains from around them. Half or less of the retained gas bubble inventory is released (Huckaby et al. 2000). Ammonia concentrations do not begin increasing until the ammoniadepleted supernatant liquid cover is pumped out and ammonia-rich wetted pore surface is exposed. If the tank ventilation rate is low, both hydrogen and ammonia concentrations can be relatively high. Saltwell pumping campaigns in U-105 and S-106 are described in Section 3.3.4 and 3.3.5, respectively, to illustrate these features. 


\subsubsection{Background Gas Releases}

Background gas releases are observed in a tank headspace during periods when the waste is not being influenced by waste-disturbing operations or undergoing a gas release event (which has been defined as a rise of more than $100 \mathrm{ppm}$ in headspace hydrogen concentration followed by an exponential decay). Seasonal temperature variations affect passive ventilation rates and gas release rates, thereby causing the background flammable gas concentrations to fluctuate considerably.

The less-soluble gases are released to the headspace at the same rate they are generated except in some tanks where a small fraction remains trapped in the waste as bubbles. This is evidenced by a gradual rise in waste level or interstitial liquid level. Ammonia, however, is so soluble that it has been estimated that $99 \%$ of the ammonia generated remains in solution in the waste (Shekarriz et al. 1997) rather than being released to the headspace.

Tank headspace monitoring and sampling consistently show that the background flammable gas concentrations are far below $25 \%$ of the LFL in all tanks, including those that are passively ventilated (Johnson et al. 2001). The highest flammability under normal ventilation is $4 \%$ of the LFL. Background release is a potential concern only under the hypothetical minimum ventilation rate produced by barometric pressure fluctuations. Hu et al. (2002) have calculated that under this reduced breathing condition (estimated at $0.45 \%$ of the tank headspace volume per day) 37 of the 177 tanks could exceed $25 \%$ of the LFL, while 10 of these could eventually reach $100 \%$ of the LFL. These results are discussed in Section 3.2.

\subsection{Joint Flammability of Flammable Gases}

The principal gases found in Hanford wastes are hydrogen, nitrous oxide, nitrogen, and ammonia. Methane and other hydrocarbons are also present but in much lower concentrations. These gases are found both in the headspaces and in gas samples obtained from core samples using the RGS (Mahoney 2000; Johnson et al. 2001). Considerable experimental work, summarized by Mahoney et al. (2000a), has been done to evaluate the flammability of these gas mixtures.

The LFL of a dilute combustible fuel mixture is the smallest concentration that just supports flame propagation when stimulated by an external ignition source. The LFL is determined by the gas composition, energy, and location of the ignition source; direction of flame propagation relative to gravity; and whether the gas is quiescent or being mixed. The gas composition effects include those associated with different oxidants (oxygen in air versus nitrous oxide) and those associated with inert constituents. At this lean limit, fuel availability is the dominant constraint on combustion.

In a quiescent atmosphere the transition to flammability is abrupt, and the LFL is higher (i.e., more fuel is required) for downward flame propagation than for upward propagation because of the buoyancy of the heated gases. Thus, the upward propagation limit (the minimum fuel concentration required for a flame to propagate upward) is lower than the downward propagation limit (the minimum fuel concentration required for a flame to propagate downward). In a 
turbulent, well-mixed atmosphere the transition to flammability is more gradual, and there is little or no difference between upward and downward propagation. Combustion pressure increases linearly as the fuel concentration increases beyond the LFL, which is essentially equal to the upward propagation limit in a quiescent atmosphere. A very energetic ignition source has an effect similar to turbulence.

The upward propagation LFLs of hydrogen and ammonia in air are 40,000 and 150,000 ppm, respectively. The effects on the LFL of the released nitrogen, an inerting gas, and nitrous oxide, a potential oxidant at high temperature, are negligible under tank conditions. Because methane and other hydrocarbons are sparingly soluble in tank liquids, they are released by escaping bubbles like hydrogen with no evaporative component. Because their measured concentration in the retained gas is small, the contribution of hydrocarbons to headspace flammability is considered negligible compared with hydrogen.

The LFL of a mixture of hydrogen and ammonia in air can be computed from the LFL of each fuel using Le Chatelier's linear mixing law (Mahoney et al. 2000a). An expression of this relationship that is useful in evaluating the flammability as a fraction of the LFL of an air/fuel mixture in a tank headspace is

$$
\frac{[\mathrm{MIX}]}{[\mathrm{MIX}]_{\mathrm{LFL}}}=\frac{\left[\mathrm{H}_{2}\right]_{\mathrm{MIX}}}{\left[\mathrm{H}_{2}\right]_{\mathrm{LFL}}}+\frac{\left[\mathrm{NH}_{3}\right]_{\mathrm{MIX}}}{\left[\mathrm{NH}_{3}\right]_{\mathrm{LFL}}}
$$

where

$[\mathrm{MIX}]_{\mathrm{LFL}}=$ volume fraction of the fuel gas mixture in air at its LFL

$[\mathrm{MIX}]=$ volume fraction of fuel gas (sum of fuel gas concentrations) in the air/fuel mixture

$[\mathrm{gas}]_{\mathrm{MIX}}=$ volume fraction of each fuel gas (assumed to be a hydrogen and ammonia) in the air/fuel mixture

$[\mathrm{gas}]_{\mathrm{LFL}}=$ the LFL of each fuel gas, expressed as a volume fraction.

The hydrogen concentration in the fuel/air mixture when it reaches its LFL can be found by setting $[\mathrm{MIX}] /[\mathrm{MIX}]_{\mathrm{LFL}}$ to unity and solving for $\left[\mathrm{H}_{2}\right]_{\mathrm{MIX}}$. Modifying Eq. (2.1) accordingly, we have

$$
\left[\mathrm{H}_{2}\right] \text { at mixture } \mathrm{LFL}=\left(\frac{1}{\left[\mathrm{H}_{2}\right]_{\mathrm{LFL}}}+\frac{\left(\left[\mathrm{NH}_{3}\right] /\left[\mathrm{H}_{2}\right]\right)_{\mathrm{MIX}}}{\left[\mathrm{NH}_{3}\right]_{\mathrm{LFL}}}\right)^{-1}
$$

The value of $\left(\left[\mathrm{NH}_{3}\right] /\left[\mathrm{H}_{2}\right]\right)_{\text {MIX }}$ in released gas is difficult to determine because the ammonia concentration is extremely difficult to measure and generally peaks later than hydrogen. Ammonia is released not only in escaping bubbles of retained gas but also by evaporation, which is its predominant path. It is therefore not uncommon for the ammonia/hydrogen ratio to be much higher in released gas than in retained gas, especially after the initial bubble release declines while evaporation continues. The potential for ammonia to become a significant flammability contributor during releases is a complication in establishing a hydrogen control limit and is the focus of discussions of some historic observations in Section 3. 


\subsection{Effect of Water Vapor on Ammonia Flammability}

The presence of water vapor in the tank headspace can be expected to have some suppressive effect on the ignition of ammonia (Khan et al. 1995; Fenton et al. 1995). Table 2.1 lists the experimental data on the effect of water vapor that have been found by the standard spark ignition method.

Two statements can be made about the effect of water. First, some water vapor pressures are high enough to completely suppress ammonia flammability. However, the waste temperatures in most Hanford tanks are low enough and dissolved salt concentrations high enough that it is impossible for most tank headspaces to contain a suppressing level of water vapor. Second, water vapor below the suppressing level still affects ammonia flammability by increasing the LFL of ammonia; however, the LFL is increased by 30 to $40 \%$ at most. Because the flammability of a gas is in inverse proportion to its LFL, the increase in ammonia LFL makes its flammability contribution decrease. The greatest effect of water vapor on the flammability contribution of ammonia is to effectively reduce it to 70 to $75 \%$ of its dry-air value. This change is not large but comparable to the uncertainties in measurements or estimates of ammonia concentration.

To estimate the waste temperatures at which the equilibrium water vapor concentration would render ammonia nonflammable, we applied the information in Table 2.1 to the measurements of water vapor pressure over two waste simulants that were made by Norton and Pederson (1994). The more dilute simulant used by Norton and Pederson was about $6 \underline{\mathrm{M}}$ in sodium, resembling SY-101 waste after 1:1 dilution with water. Their concentrated simulant was about $12 \underline{\mathrm{M}}$ in sodium, resembling undiluted saturated saltcake liquid.

Consider the conditions controlling whether the headspace water vapor concentration is high enough to suppress ammonia flammability. The tank headspace temperature (rather than the waste temperature) determines the maximum water vapor concentration that will allow $\mathrm{NH}_{3}$ to burn. Headspace temperatures range from $20^{\circ}$ to $50^{\circ} \mathrm{C}$, which (based on the literature data summarized in Table 2.1) means the maximum water vapor concentration consistent with ammonia combustion is between 8 and 9 vol\%.

Table 2.1. Effect of Water Vapor on Ammonia Ignition

\begin{tabular}{|c|c|c|l|}
\hline $\begin{array}{c}\text { Initial } \\
\text { Temperature } \\
\left({ }^{\mathbf{0}} \mathbf{C}\right)\end{array}$ & Vol\% water & $\begin{array}{c}\text { Vol\% Ammonia } \\
\text { at LFL }\end{array}$ & \multicolumn{1}{|c|}{ Reference } \\
\hline 25 & 3.2 & 16.0 & Khan et al. (1995) \\
\hline 25 & 4 & 17.3 & Cited by Fenton et al. (1995) \\
\hline 25 & $\begin{array}{c}8.2(\max \text { that } \\
\text { allows ignition) }\end{array}$ & 21 & Cited by Fenton et al. (1995) \\
\hline 44 & $8.8(\max )$ & 21 & Cited by DeCoursey et al. (1962) \\
\hline 65 & 4 & 17.6 & Cited by DeCoursey et al. (1962) \\
\hline 65 & $10(\max )$ & 21 & Cited by DeCoursey et al. (1962) \\
\hline 80 & 4 & 16.8 & Cited by DeCoursey et al. (1962) \\
\hline 80 & $10.8(\max )$ & 20 & Cited by DeCoursey et al. (1962) \\
\hline
\end{tabular}


The waste liquid temperature and salt content, together with the ventilation rate and the mass-transfer limits on evaporation, determine the water concentration that exists over the waste. For pure salt-free water an equilibrium water vapor concentration of $8-9 \mathrm{vol} \%$ is achieved at a liquid temperature of about $43^{\circ} \mathrm{C}$. Thus, for the tanks where the liquid is a very dilute salt solution, ammonia combustion could be suppressed if the waste temperature was above $43^{\circ} \mathrm{C}$ and if water equilibrium was reached above the waste. For the dilute waste simulant (about $6 \underline{\mathrm{M}}$ $\mathrm{Na}$ ) used by Norton and Peterson (1994), the requisite liquid temperature was about $50^{\circ} \mathrm{C}$. For their concentrated simulant (about $12 \underline{\mathrm{M} \mathrm{Na}}$ ), the requisite liquid temperature was about $62^{\circ} \mathrm{C}$.

It would be inaccurate to declare that the headspaces of wastes whose surfaces are above the stated temperatures are safe from ammonia ignition. The headspace water vapor, like the headspace ammonia vapor, may be at concentrations below the equilibrium value for a combination of conditions: mass-transfer limitations on evaporation (particularly on evaporation from waste without an open liquid surface), condensation on cool tank surfaces, and ventilation with air at lower humidity. Water vapor will probably approach equilibrium more closely than ammonia vapor because water is not significantly depleted in the near-surface liquid by evaporation (unlike ammonia). For every $20 \%$ by which the headspace water vapor pressure is less than equilibrium, the maximum temperature for ammonia ignition increases by roughly $5^{\circ} \mathrm{C}$.

However, the conditions of concern in setting the hydrogen action limit are those that produce high evaporation of ammonia, which are also those in which water evaporates readily. Therefore, we ignore the nonequilibrium effects that decrease the water vapor in the headspace. Considering the equilibrium temperatures only, we note that there are only 25 tanks with average waste temperatures of $43^{\circ} \mathrm{C}$ or higher. Of these, all but a few contain substantial salt. There are 20 tanks with average waste temperatures of $50^{\circ} \mathrm{C}$ or higher and 11 tanks above $62^{\circ} \mathrm{C}$. The large majority of tank wastes are not hot enough to suppress ammonia flammability. Most would only produce enough water vapor, under the most evaporative conditions, to decrease the ammonia LFL by $20 \%$ or less. 


\subsection{Observations}

The actual LFL of a gas mixture in a tank depends on which flammable gases are present in what concentrations. Pure hydrogen has an LFL of 4 vol\% (40,000 ppm) in air. Pure ammonia in air has an LFL of $15 \mathrm{vol} \%(150,000 \mathrm{ppm})$ (Mahoney et al. 2000a). If hydrogen were the only flammable gas, a control limit set at $25 \%$ of LFL would be $10,000 \mathrm{ppm}$. When other fuel gases are present with hydrogen and only hydrogen is measured, a lower hydrogen value is required to indicate $25 \%$ of the LFL of the gas mixture.

The control limit was set at $6,250 \mathrm{ppm}$ of hydrogen (Estey 1998). This limit is $25 \%$ of the hydrogen concentration of a mixture containing $2.5 \mathrm{vol} \%$ hydrogen and $2 \mathrm{vol} \%$ ammonia (an ammonia/hydrogen ratio of 0.8$)$. Eq. (2.2) shows that this mixture is just flammable $(100 \%$ LFL) assuming very conservative values of $3.5 \mathrm{vol} \%(35,000 \mathrm{ppm})$ for the LFL for pure hydrogen and 8 vol\% $(80,000 \mathrm{ppm})$ for ammonia. Using the accepted LFL values for hydrogen (4 vol\%) and ammonia (15 vol\%) this same mixture would be $76 \%$ of the LFL, and a hydrogen concentration of $8,200 \mathrm{ppm}$ would represent $25 \%$ of the LFL. A hydrogen concentration of $6,250 \mathrm{ppm}$ would be only $19 \%$ of the LFL.

The conservatism inherent in setting the control limit at $6,250 \mathrm{ppm}$ hydrogen is put into perspective in Figures 3.1 and 3.2. Figure 3.1 shows the fraction of the mixture LFL with increasing ammonia concentration for a fixed hydrogen concentration of $6,250 \mathrm{ppm}$. The plot shows that, if no ammonia is present, $6,250 \mathrm{ppm}$ hydrogen is equivalent to $16 \%$ of the LFL. Also, it takes 12.7 vol\% (126,600 ppm) ammonia for the mixture to reach $100 \%$ of the LFL and $14,060 \mathrm{ppm}$ ammonia for $25 \%$ of the LFL. Figure 3.2 shows the hydrogen concentration necessary to reach $100 \%$ and $25 \%$ of the LFL, respectively, as the ammonia concentration increases.

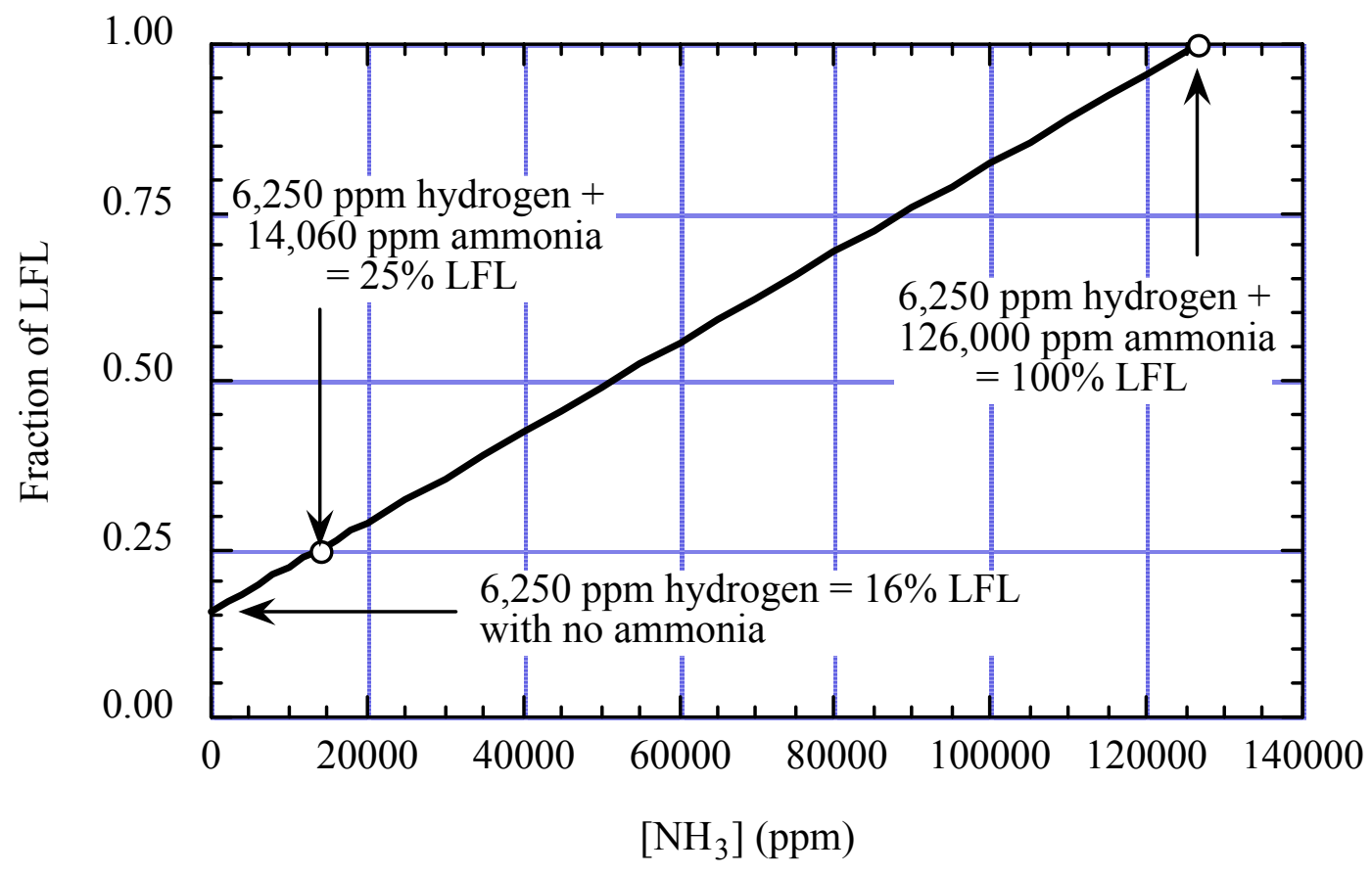


Figure 3.1. Mixture Flammability with 6,250 ppm Hydrogen

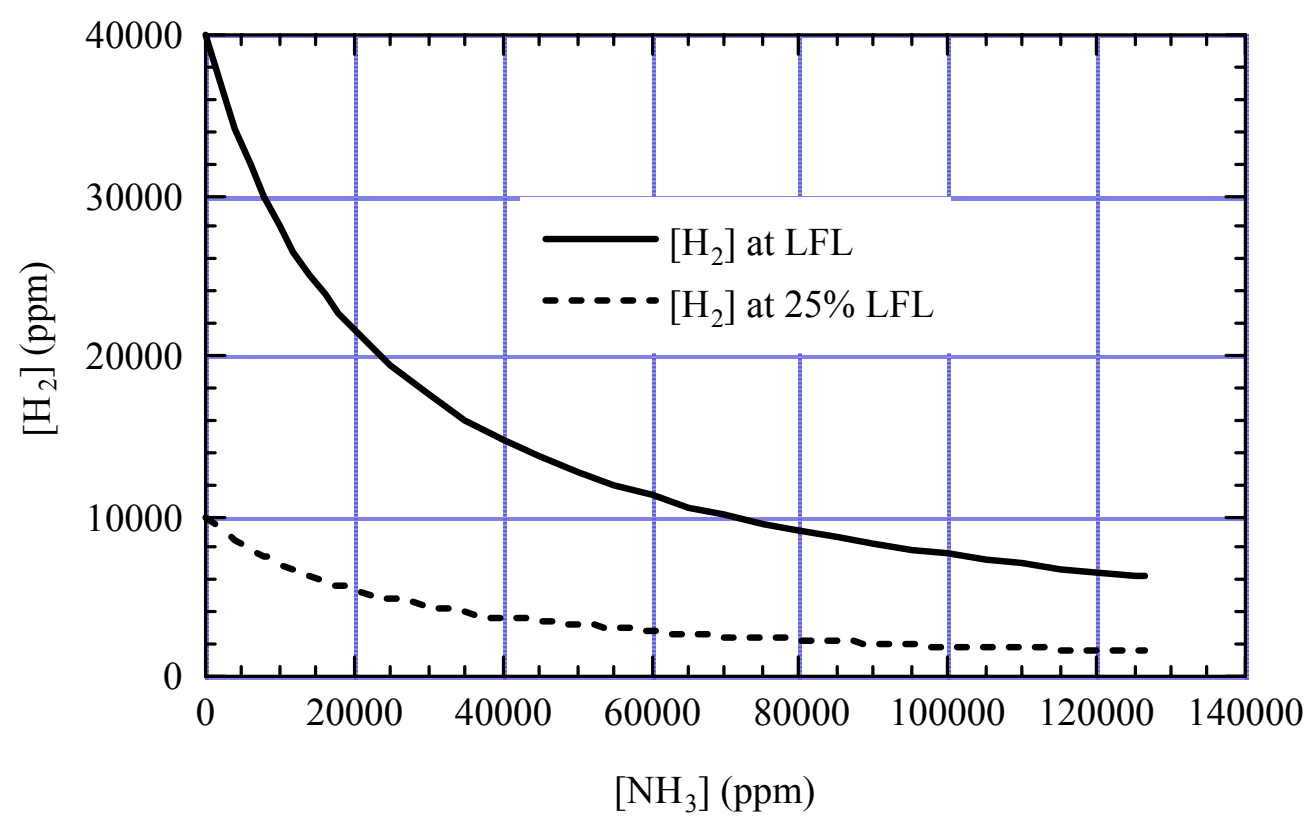

Figure 3.2. Hydrogen Concentration for $100 \%$ and $25 \%$ LFL Versus Ammonia Concentration

With no ammonia present, a hydrogen concentration of $10,000 \mathrm{ppm}$ is $25 \%$ of the LFL. The hydrogen concentration for $25 \%$ of the LFL drops to $6,250 \mathrm{ppm}$ at $14,060 \mathrm{ppm}$ ammonia and to $4,000 \mathrm{ppm}$ hydrogen at $35,000 \mathrm{ppm}$ ammonia. The highest ammonia concentration actually measured in a tank headspace was 7,400 ppm in SY-102 while it was receiving waste from SY-101 in March 2000 (Mahoney et al. 2000b). A higher ammonia concentration of 13,000 ppm was estimated in June 1993 in SY-101, while the monitoring instrument went off the scale during the last major BDGRE. This measurement is of dubious value because it was off-scale and was both preceded and followed by periods of substantial data scatter. The ammonia value of 126,000 ppm in Figures 3.1 and 3.2 is not considered credible. It would require a combination of high dissolved ammonia, high temperature, and vigorous stirring or bubbling in the waste liquid to allow equilibrium to be reached.

The evidence presented above builds a strong case that the 6,250-ppm hydrogen limit is conservative, perhaps overly conservative. However, data from more recent operations discussed below reveal that these higher values may not be adequate in all cases and the 6,250 ppm hydrogen limit is reasonable. The rest of this section evaluates the evidence available to elucidate these issues. Section 3.1 establishes the maximum possible ammonia concentration that occurs when the vapor space is in equilibrium with the liquid waste. Section 3.2 describes steady-state or background gas concentrations, and Section 3.3 discusses specific spontaneous and induced gas releases with particularly high hydrogen and ammonia concentrations. Section 3.4 summarizes the results of various gas release modeling efforts. 


\subsection{Maximum Ammonia Concentration}

Figure 3.1 showed that a mixture of $6,250 \mathrm{ppm}$ hydrogen with more than $14,060 \mathrm{ppm}$ ammonia would exceed $25 \%$ of the LFL and would reach the full LFL with an ammonia concentration of $126,000 \mathrm{ppm}$ (the latter concentration not being considered credible). Therefore, to evaluate whether the $6,250 \mathrm{ppm}$ hydrogen control limit is adequate, we need to know how high the headspace ammonia concentration might become. The maximum possible ammonia concentration occurs when the vapor is in equilibrium with the liquid and the ammonia partial pressure is equal to the vapor pressure of the dissolved ammonia in the liquid. The theoretical equilibrium ammonia concentration in the headspace may be calculated from the dissolved ammonia concentration in the liquid, dissolved salt concentration, and temperature.

Dissolved ammonia concentrations have been measured in 51 tanks (23 DSTs and 28 SSTs). The Tank Waste Information Network System (TWINS) automated internet database (http://twins.pnl.gov:8001/TCD/main.html) lists dissolved ammonia concentrations in liquid samples (supernate grab samples and drainable liquid from core samples) of 46 tanks. The BestBasis Inventory (BBI) available through TWINS gives dissolved ammonia concentrations for 21 tanks. Ammonia concentrations in the liquid and in the retained gas, which represents the equilibrium concentration inside trapped bubbles, were obtained with the retained gas sampler (RGS) for 14 tanks (Mahoney et al. 1999), 12 of which are also covered by TWINS or BBI. Hedengren et al. (2000a) calculated equilibrium ammonia concentrations at 1 atm for 19 tanks based on the highest recorded dissolved ammonia concentration from either TWINS or RGS.

Table 3.1 lists the maximum dissolved and equilibrium ammonia concentrations in tanks for which an equilibrium concentration estimate was derived from RGS data or calculated by Hedengren et al. (2000a).

The maximum equilibrium ammonia concentration exceeds $14,000 \mathrm{ppm}$ (1.4 vol\%) in AX-101, SX-103, SY-101, SX-106, SX-105, SX-102, A-101, S-102 and SX-104. The SX tanks have high equilibrium concentrations because they have both high waste temperatures and high dissolved ammonia concentrations. SY-101 originally had moderate temperatures and the highest ammonia level of any tank sampled by the RGS; ${ }^{\text {(a) }}$ however, water dilution in early 2000 has greatly reduced its ammonia concentration and waste temperature, so this tank is no longer a concern for ammonia.

The last column in Table 3.1 gives the percentage of the LFL for a mixture of $6,250 \mathrm{ppm}$ hydrogen and the equilibrium ammonia concentration. The maximum equilibrium ammonia concentration in the table is $8.4 \mathrm{vol} \%$, or $84,000 \mathrm{ppm}$, in AX-101. A mixture of $6,250 \mathrm{ppm}$ hydrogen and $84,000 \mathrm{ppm}$ ammonia would be $72 \%$ of the LFL. The equilibrium ammonia concentration in three other tanks (ignoring SY-101) would exceed $50 \%$ of the LFL if mixed with 6,250 ppm hydrogen: SX-103, 105, and 106.

Table 3.1. Ammonia Concentration in Liquid and Equilibrium Gas Concentration

(a) Two partial RGS segments in the SY-101 crust layer actually measured above 15 vol\% ammonia. However, these are discounted because of poor recovery and because the SY-101 crust was a unique artifact of long-term mixer pump operation. 


\begin{tabular}{|c|c|c|c|c|}
\hline Tank & $\begin{array}{c}\text { Max }\left[\mathrm{NH}_{3}\right] \\
\text { in Liquid } \\
(\mu \mathrm{g} / \mathrm{mL})\end{array}$ & $\begin{array}{c}\text { Peak Waste } \\
\text { Temp } \\
\left({ }^{\circ} \mathrm{F}\right)\end{array}$ & $\begin{array}{c}\text { Max Equilibrium } \\
{\left[\mathrm{NH}_{3}\right]} \\
(\mathrm{vol} \%) \\
\end{array}$ & $\begin{array}{l}\text { \%LFL with } \\
\text { 6,250 ppm } \\
\text { Hydrogen }\end{array}$ \\
\hline AX-101 & 4100 & 120 & 8.4 & 72 \\
\hline SX-103 & 1800 & 148 & 7.4 & 65 \\
\hline SY-101 ${ }^{\text {(a) }}$ & 4600 & 120 & 6.4 & 58 \\
\hline SX-106 & 2500 & 93 & 5.5 & 52 \\
\hline SX-105 & 1210 & 148 & 5.4 & 51 \\
\hline SX-102 & 1370 & 136 & 3.9 & 42 \\
\hline A-101 & 1400 & 137 & 3.5 & 39 \\
\hline S-102 & 1700 & 96 & 1.9 & 28 \\
\hline SX-104 & 793 & 134 & 1.8 & 28 \\
\hline AN-103 & 680 & 99 & 1.4 & 25 \\
\hline U-109 & 1100 & 82 & 1.2 & 24 \\
\hline S-111 & 1500 & 85 & 1.1 & 23 \\
\hline U-105 & 1600 & 82 & 0.9 & 22 \\
\hline BY-105 & 1030 & 103 & 0.9 & 21 \\
\hline AN-104 & 580 & 103 & 0.9 & 22 \\
\hline S-109 & 1550 & 80 & 0.8 & 21 \\
\hline U-103 & 1400 & 81 & 0.8 & 21 \\
\hline S-103 & 1410 & 78 & 0.6 & 20 \\
\hline AN-105 & 620 & 97 & 0.6 & 20 \\
\hline AW-101 & 580 & 95 & 0.6 & 20 \\
\hline SX-101 & 132 & 123 & 0.5 & 19 \\
\hline U-102 & 745 & 81 & 0.4 & 18 \\
\hline S-106 & 430 & 72 & 0.3 & 18 \\
\hline BY-109 & 250 & $\mathrm{n} / \mathrm{a}$ & 0.2 & 17 \\
\hline U-107 & 403 & 76 & 0.1 & 17 \\
\hline
\end{tabular}

Table 3.2 gives the dissolved ammonia concentrations for tanks for which no equilibrium calculation is available. Comparing the dissolved ammonia concentrations and temperatures in this table with those of Table 3.1, it appears that only S-112, SY-102 and C-103 might have equilibrium ammonia concentrations of 1 to $4 \mathrm{vol} \%$.

The data presented in this section show that it is not possible for a mixture of $6,250 \mathrm{ppm}$ hydrogen and ammonia to reach the LFL. In fact, the bounding mixture will be below $25 \%$ of the LFL in most tanks. However, these data represent less than $1 / 3$ of the total number of tanks, and ammonia concentrations are also extremely difficult to measure and tend to be biased on the low side (Mahoney 2000). Therefore, it is possible that other tanks may have equally high or higher equilibrium ammonia concentrations. Nevertheless, it must be emphasized that the bounding ammonia concentration can be approached only if the waste is stirred to prevent the liquid surface from becoming depleted of ammonia and headspace ventilation is minimal to prevent dilution of ammonia already evolved from the surface. These conditions are not likely to occur in any anticipated operation, as will be demonstrated in the rest of this section. 
Table 3.2. Dissolved Ammonia Concentration in Liquid

\begin{tabular}{||l|c|c|}
\hline Tank & $\begin{array}{c}\text { Max. }\left[\mathbf{N H}_{3}\right] \text { in } \\
\text { Liquid } \\
(\mu \mathbf{g} / \mathbf{m L})\end{array}$ & $\begin{array}{c}\text { Peak Waste } \\
\text { Temp. } \\
\left({ }^{\mathbf{}} \mathbf{F}\right)\end{array}$ \\
\hline S-112 & 2150 & 80 \\
\hline SY-102 & 1830 & 85 \\
\hline C-103 & 1600 & 114 \\
\hline AP-107 & 1140 & 62 \\
\hline AW-105 & 1010 & 65 \\
\hline AP-108 & 800 & 64 \\
\hline S-107 & 677 & 100 \\
\hline AP-104 & 650 & 74 \\
\hline U-111 & 533 & 77 \\
\hline AW-103 & 512 & 72 \\
\hline S-101 & 506 & 108 \\
\hline AP-105 & 324 & 70 \\
\hline AP-103 & 254 & 67 \\
\hline S-110 & 193 & 108 \\
\hline AW-104 & 169 & 73 \\
\hline AZ-101 & 125 & 180 \\
\hline SY-103 & 108 & 93 \\
\hline AW-102 & 74 & 67 \\
\hline AY-102 & 74 & 150 \\
\hline AP-106 & 68 & 73 \\
\hline AN-107 & 51 & 91 \\
\hline AN-101 & 40 & 68 \\
\hline AY-101 & 37 & 108 \\
\hline BY-103 & 10 & 65 \\
\hline AP-101 & 2 & \\
\hline & & 67 \\
\hline
\end{tabular}

\subsection{Background Headspace Gas Concentrations}

A distinction is made between discrete gas release events that occur over a few hours or a few days and background release between events. Hanford waste tanks do not exhibit a true steady state in the sense of a constant or asymptotic value. Seasonal changes in waste temperature, fluctuations in barometric pressure, random changes in gas release behavior, and variations in passive ventilation rates in SSTs cause gas concentrations to drift considerably. Long-term headspace gas monitoring provides a good average of the background concentrations. Hydrogen is typically monitored, but ammonia data are available for only a few tanks. Headspace monitoring has consistently shown very low flammable gas concentrations under normal ventilation (McCain 2001).

Background gas release is a concern only for the hypothetical low ventilation rates assumed for accident analyses. For these, the ventilation rate is limited to barometric breathing, which exchanges only $0.45 \%$ of the headspace volume per day. This is equivalent to $0.5 \mathrm{cfm}$ or less, an order of magnitude less than most measured passive ventilation rates (Huckaby et al. 1998). 
$\mathrm{Hu}$ et al. (2002) calculated the background headspace flammability for both normal and barometric breathing for all 177 DSTs and SSTs. The flammability calculation included both hydrogen and ammonia concentrations estimated from models supported by sampling and monitoring data. The results showed that background flammable gas concentrations under normal ventilation are less than $5 \%$ of the LFL and are typically less than $1 \%$ of the LFL (Hu et al. 2002). However, under barometric breathing some tanks reached as much as twice the LFL.

The 6,250 ppm hydrogen control limit would conservatively represent $25 \%$ of the LFL for background releases under barometric breathing in the majority of tanks. Figure 3.3 shows the cumulative distribution over all 177 tanks of the fraction of the LFL of a mixture of 6,250 ppm hydrogen calculated from Eq. (2.1) using the ammonia/hydrogen ratio derived from $\mathrm{Hu}$ et al. (2002). The figure shows that $6,250 \mathrm{ppm}$ hydrogen would represent less than $26 \%$ of the LFL in $95 \%$ of the tanks and less than $29.5 \%$ in all tanks. The $6,250 \mathrm{ppm}$ limit is associated with a lower joint flammability for background releases (Figure 3.3) than for hypothetical equilibrated releases (Table 3.1) because the background releases are not near equilibrium $\mathrm{NH}_{3}$ conditions.



Figure 3.3. Distribution of Fraction of $\mathrm{LFL}$ with $\left[\mathrm{H}_{2}\right]=6,250 \mathrm{ppm}$ for Barometric Breathing

\subsection{Spontaneous and Induced Gas Releases}

Our approach in reviewing these data is to start from historical events and calculate the flammability in the headspace over time, including both hydrogen and ammonia. We also calculate what the hydrogen concentration would have been if the gas release had the same composition but sufficient quantity to reach $25 \%$ of its LFL in the headspace. We then consider what mechanisms of release were at work and whether, for plausibly different ventilation or source concentrations, those same mechanisms could have produced high flammability coincident with a high ammonia/hydrogen ratio. We also estimate how close the releases came to producing an 
equilibrium ammonia concentration in the headspace, as a way of checking the assumption (stated in Section 3.1) that headspace concentrations seldom or never approach equilibrium.

The concentration is on historical events because of the difficulty in calculating applicable mass transfer rates from theoretical mass transfer models. To maintain the proper perspective on the effects of a high ammonia concentration, recall that if 6,250 ppm hydrogen were present in the tank headspace, $14,060 \mathrm{ppm}$ of ammonia would be required for $25 \%$ of the LFL and $126,000 \mathrm{ppm}$ ammonia is needed for $100 \%$ of the LFL.

Two BDGREs in SY-101 are considered in Section 3.3.1, and gas releases in SY-101 caused by transfer and back-dilution are described in Section 3.3.2. Gas releases induced in SY-102 when it was receiving waste from SY-101 are covered in Section 3.3.3. Saltwell pumping in U-105, S-106, and S-111 are summarized in Sections 3.3.4, 3.3.5, and 3.3.6, respectively.

\subsubsection{SY-101 Spontaneous Gas Releases}

The BDGREs in Tank SY-101 are of interest because they have produced the highest flammability that has been measured in the headspace and because (before mitigation) SY-101 had the highest dissolved ammonia concentration measured by the RGS in any Hanford waste tank (Mahoney et al. 2000a). The last (but not largest) two major BDGREs in Tank SY-101 occurred in June and August 1993, before regular mixer pump operation began.

The June 26, 1993 BDGRE was observed to cause multiple large upwellings of liquid and motion of the entire waste surface (Meyer et al. 1997). Figure 3.4 and similar figures for other gas releases discussed in Section 3.3 are intended to show the effect of ammonia in reducing the hydrogen concentration required to represent $25 \%$ of the LFL. The figure shows the measured hydrogen and ammonia concentration as well as the calculated hydrogen concentration that would represent $25 \%$ of the LFL given the measured ammonia/hydrogen ratio during the event. Figure 3.4 indicates that the hydrogen concentration peaked at almost 32,000 ppm, near the 40,000 ppm LFL for hydrogen alone. Ammonia was only a minor contribution to flammability, peaking at $1,070 \mathrm{ppm}$. A hydrogen concentration of $8,000 \mathrm{ppm}$ would have conservatively represented $25 \%$ of the LFL throughout the event, and the current control limit of 6,250 ppm hydrogen would have been very conservative.

It is possible that the ammonia concentration during the June 26, 1993 GRE was briefly much higher than the accepted data indicate. At one point, the ammonia measurements went offscale, with high concentrations before and after. The off-scale datum was interpreted as indicating a concentration of $13,000 \mathrm{ppm}$, but no completely plausible determination could be made. $^{\text {(a) }}$

(a) Personal communication to LA Mahoney, from DA Reynolds (April 1, 2002) and WB Barton (email, May 5, 1999), CH2MHILL Hanford Group, Inc., Richland, WA. 


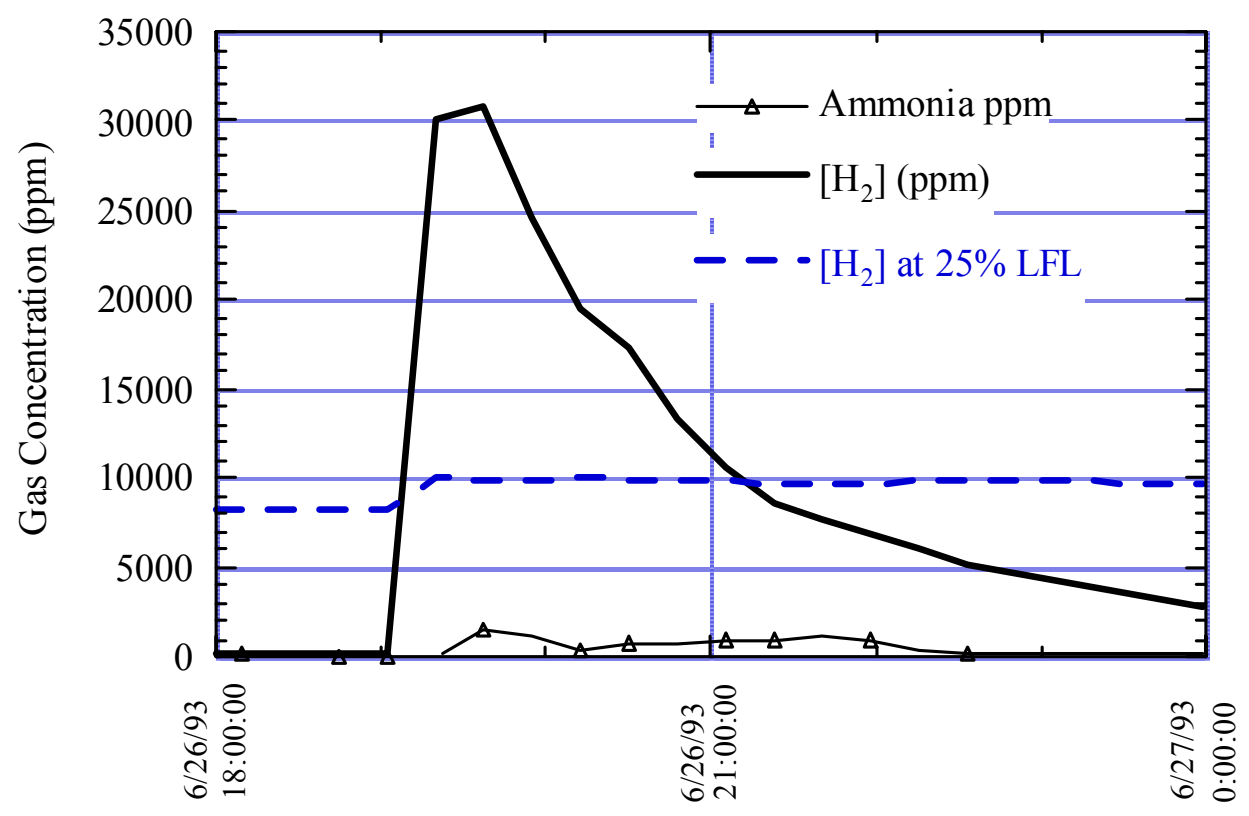

Figure 3.4. Hydrogen and Ammonia in SY-101 During the June 26, 1993 BDGRE

The ammonia/hydrogen ratios during the peak gas release period were less than 0.1. By comparison, RGS data for SY-101 (Mahoney et al. 1999; Mahoney 2000) indicated that the ammonia/hydrogen ratios in the retained gas were in the range of 0.2 to 0.7 . It is probable that evaporative releases were only a small part of the flammable gas release in the June GRE (if it is assumed, as seems reasonable, that the 13,000 ppm estimate was invalid). However, ammonia made up a somewhat larger proportion of the August 27, 1993 gas release discussed below.

Figure 3.5 shows the measured hydrogen and ammonia concentrations and the calculated hydrogen concentration to reach 25\% of the LFL for the BDGRE of August 27, 1993. In this event, the highest measured ammonia concentration was $3,070 \mathrm{ppm}$, hydrogen peaked at just over $6,000 \mathrm{ppm}$, and ammonia/hydrogen ratios were between 0.5 and 0.6 . The mixture flammability peaked at $17.5 \%$ of the LFL. Again, $25 \%$ of the mixture LFL would have been well represented by 8,000 ppm hydrogen.

Consistent with Table 3.1, the undiluted SY-101 waste, with its ammonia concentration of 0.35 to 0.5 molal and a temperature of about $50^{\circ} \mathrm{C}$, would have had an ammonia equilibrium partial pressure that corresponded to a concentration of $64,000 \mathrm{ppm} \mathrm{NH}_{3}$ in the headspace (Table 3.1). The measurements from these two BDGREs indicate that, at most, $5 \%$ of equilibrium $\mathrm{NH}_{3}$ was reached in the headspace.

In the two GRE examples, the data show that a hydrogen control limit as high as $8,000 \mathrm{ppm}$ hydrogen could have been used, historically, for $25 \%$ of LFL. Next, consider the SY-101 GREs 
as examples of any plausible mechanism producing rapid spontaneous release of retained gas and a short-term disturbance of the tank waste surface that temporarily increases ammonia evaporation. We wish to decide whether, in another tank with releases of similar rapidity and surface disturbance, a given hydrogen control limit would be less conservative because of a higher concentration of dissolved ammonia, a lower hydrogen fraction in the gas, or lower ventilation rates.

SY-101 had the highest dissolved ammonia concentration measured with the RGS, one of the lowest retained gas hydrogen fractions ( $30 \mathrm{vol} \%)$, and a relatively high waste temperature $\left(50^{\circ} \mathrm{C}\right)$ during this period. All these factors exacerbate ammonia releases and increase the ammonia/ hydrogen ratio. A ventilation flow rate that was lower than the high flow maintained in SY-101 would increase the absolute concentrations of hydrogen and ammonia in the headspace but not significantly change the ammonia/hydrogen ratio, which determines the control limit. Therefore, SY-101 BDGREs set a reasonable upper bound for spontaneous rapid releases of retained gas and indicate that such releases are very conservatively covered by the 6,250 ppm hydrogen control limit.

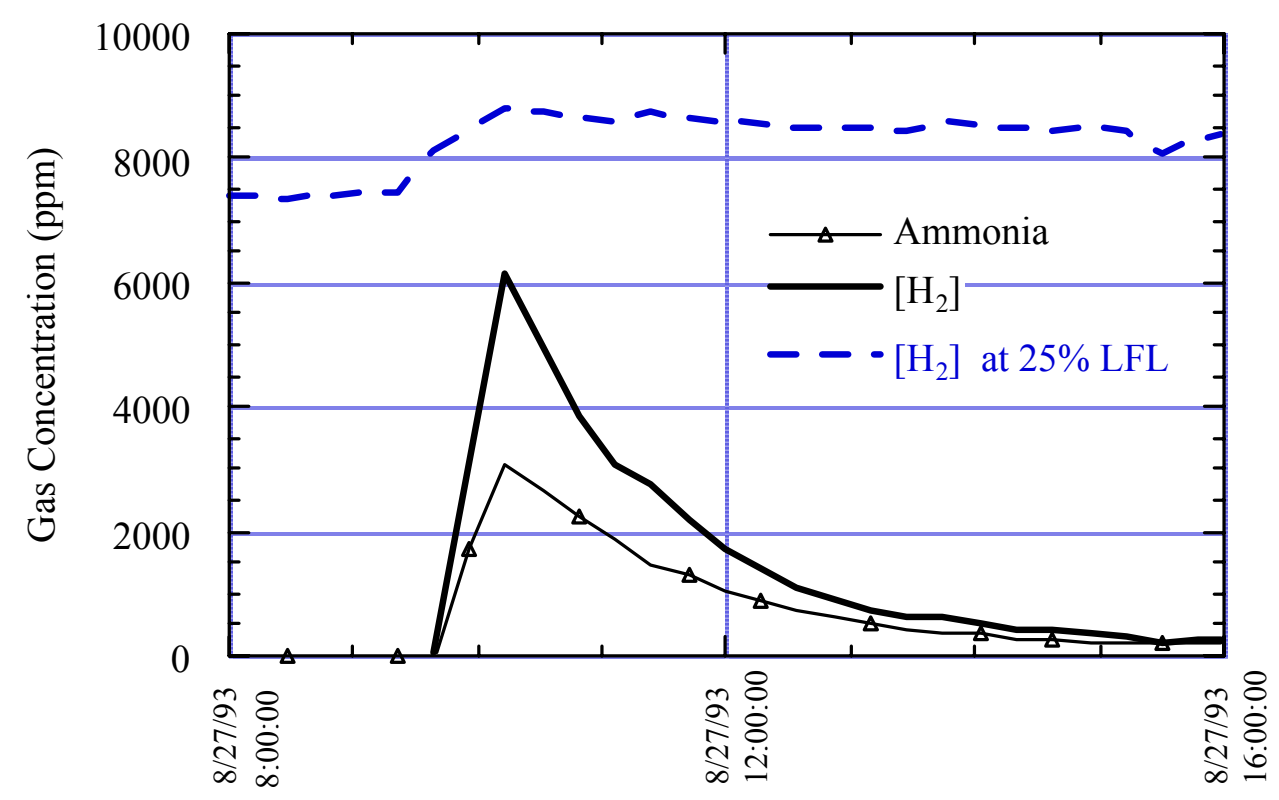

Figure 3.5. Hydrogen and Ammonia in SY-101 During the August 27, 1993 BDGRE

\subsubsection{SY-101 During Waste Dilution and Transfer}

At the end of 1999 and beginning of 2000, the waste in SY-101 underwent a series of dilutions and transfers that are described in detail by Mahoney et al. (2000b). The largest gas releases during the campaigns that are of most interest for this report, were a series of bubble slurry flows or small eruptions of gas and entrained liquid onto the waste surface. The slurry consisted of a foamy white flow sometimes accompanied by small waves on the liquid surface. 
Figure 3.6 shows the measured hydrogen and ammonia concentrations and the calculated hydrogen concentration representing $25 \%$ of the LFL in the SY-101 headspace during and after the early part of Campaign 2. The waste transfer to Tank SY-102 began at 4:22 PM on January 25, 2000 and continued without interruption or change in flow rate until 10:07 PM on January 27. The transfer produced a continuous, apparently constant, release rate of hydrogen and a release rate of ammonia that gradually increased and then leveled off. The hydrogen release ended when the transfer did; the ammonia release ended when water was added on top of the waste, beginning at 1:43 AM and ending at 10:19 PM on January 28, 2000. The series of bubble slurry flows began several hours after top-dilution was started.

The peak flammability produced by the bubble slurry flows was 5\% of LFL. The peak concentrations of hydrogen and ammonia were $1,960 \mathrm{ppm}$ and $720 \mathrm{ppm}$, respectively. These peaks occurred during two different slurry flows, but the peak hydrogen in both cases was near $1,900 \mathrm{ppm}$, indicating that similar volumes of bubbles were released and making it legitimate to consider the possibility that the highest hydrogen and ammonia concentrations could just as easily have occurred in the same release. The peak ammonia represented a few percent of the estimated equilibrium concentration. (In this case, the equilibrium ammonia concentration in the headspace is difficult to estimate because the dissolved ammonia concentration might have been lowered by in-tank dilution.)

The ammonia/hydrogen ratios were about 0.1 in the first peak (at the end of January 28, 2000) but ranged between 0.3 and 0.6 in the second peak (on January 29, 2000). We believe the difference in ratios was caused by entrainment in the slurry flow of waste liquid that was more or less diluted by the top-dilution water during the first peak.

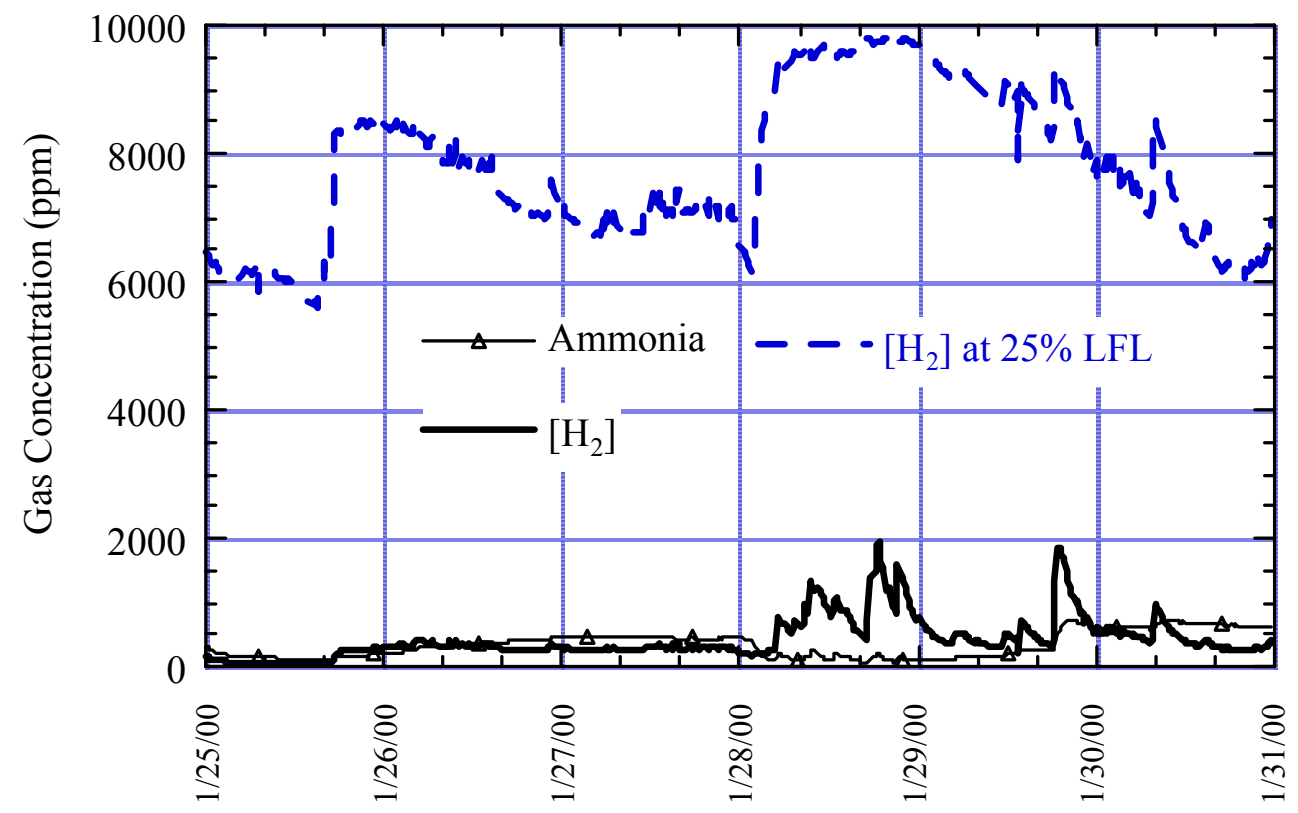

Figure 3.6. Hydrogen and Ammonia in SY-101 During Second Waste Transfer and Dilution 
As with the SY-101 BDGREs, the bubble slurry flows were dominated by rapid bubble release. The large number of slurry flows that occurred-eight that exceeded 1,000 ppm hydrogen plus about as many smaller ones-gives some reassurance that the "statistical population" of release volumes was fully represented. If that were the case, such events (even if they occurred in another tank under similar top-dilution conditions) would not be so different in mechanism as to produce much larger gas releases.

As shown in Figure 3.6, 25\% of LFL consistently corresponded to 8,000 ppm hydrogen or more for the peak concentrations from the historical SY-101 bubble slurry flows. These flows can be considered generic examples of small spontaneous rapid releases of retained gas that might occur during some operations in SSTs (possibly including dissolution) as well as in DSTs. Based on arguments made for the SY-101 BDGREs in Section 3.3.1, we consider it unlikely that conditions in any other tanks with similar release mechanisms would produce higher ammonia/hydrogen ratios that would require a lower control limit. The absolute hydrogen and ammonia concentrations, given the same release mechanism in another tank, would depend on the tank ventilation rate and could be higher.

\subsubsection{SY-102 During Waste Transfer}

The waste transferred from SY-101 to SY-102 during late 1999 and early 2000 produced flammability of nearly 5\% of LFL in the SY-102 headspace. Most of the flammability was contributed by ammonia evaporation because the hydrogen inventory was limited to the small amount dissolved in the incoming liquid. The transferred waste entered beneath the surface of the SY-102 waste. The relatively high ammonia release rate during transfer is believed to have been caused by ammonia "scrubbing" by bubbles of air entrained by the siphon break in the drop leg through which waste entered SY-102. Once transfer stopped and the air sparging ended, the ammonia release mechanism returned to stagnant surface evaporation alone, which allowed only slow releases.

Figure 3.7 shows the measured hydrogen and ammonia concentrations and the calculated hydrogen concentration for $25 \%$ of the LFL in the SY-102 headspace during the first waste transfer from SY-101 from December 18 to December 19, 1999. The average in-line dilution ratio was $0.9: 1$, with further dilution occurring as the transferred waste mixed with the more dilute low-ammonia waste already stored in SY-102. The peak ammonia concentration was almost 2,000 ppm, with $240 \mathrm{ppm}$ peak hydrogen. The large ammonia/hydrogen ratio indicated that $25 \%$ of the LFL would have been represented by less than 4,600 ppm hydrogen during this transfer.

Figure 3.8 shows the gas concentrations in SY-102 during the third waste transfer from SY-101. This transfer actually consisted of two operations with an eight-hour break between them. The in-line dilution ratio was 0.33:1 compared with 0.9:1 in the first transfer, and the transfer rate was $200 \mathrm{gpm}$ compared with $120 \mathrm{gpm}$ in the first transfer. The peak hydrogen concentration in the SY-102 headspace during the third transfer was 94 ppm, less than half the $240 \mathrm{ppm}$ peak during the first transfer. The dissolved ammonia content of the waste in SY-102 


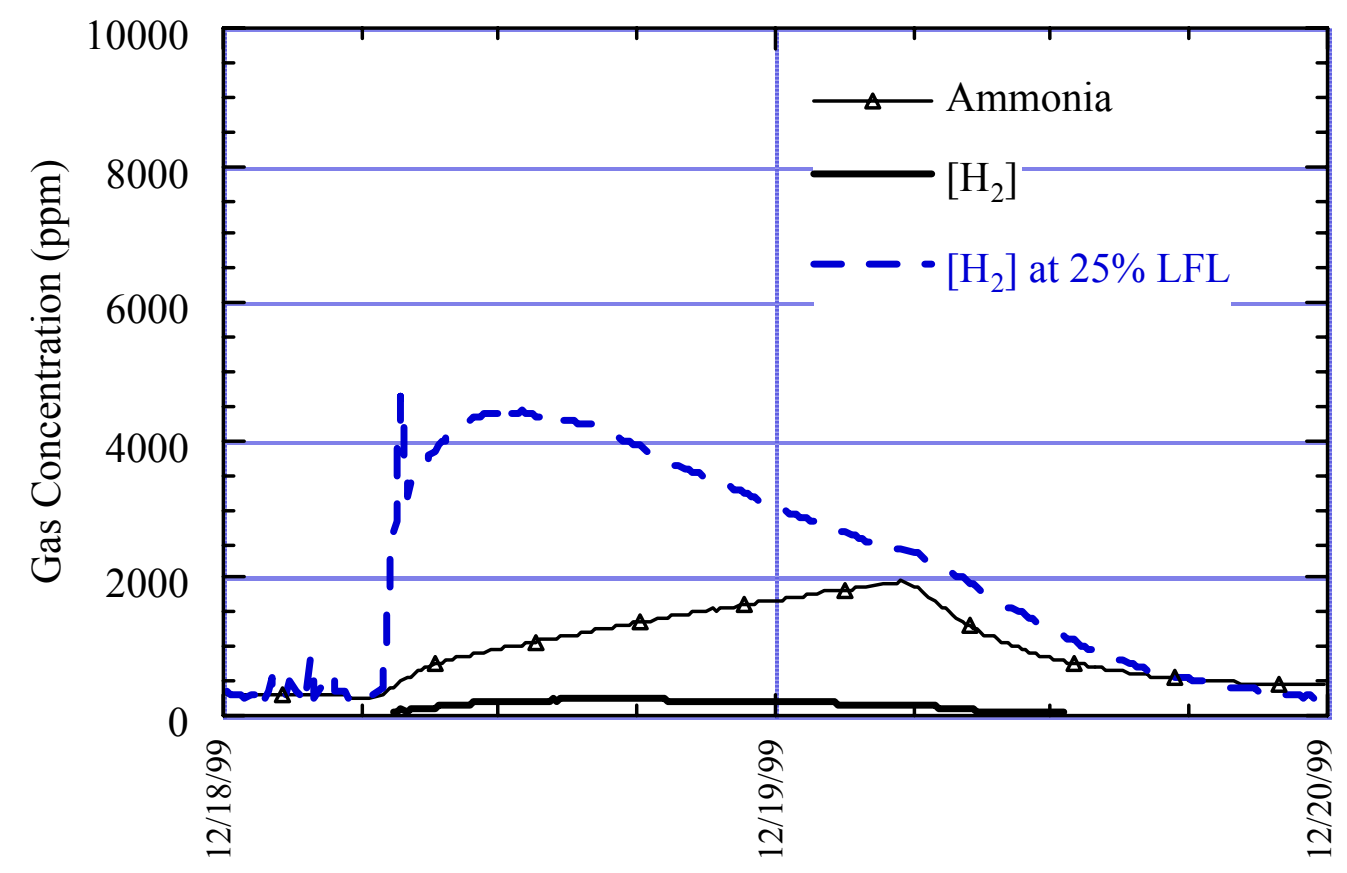

Figure 3.7. Hydrogen and Ammonia in SY-102 During First Transfer from SY-101



Figure 3.8. Hydrogen and Ammonia in SY-102 During Third Waste Transfer 
was also much greater than it was in the first transfer because it had already received two transfers of ammonia-laden SY-101 waste. The drop in ammonia concentration around March 2, 2000 was caused by a temporary reduction in the transfer rate back to $110 \mathrm{gpm}$ to control the ammonia concentration. The elevated ammonia concentration required less than 2,000 ppm hydrogen for $25 \%$ of the LFL, far less than the 6,250-ppm control limit.

The equilibrium partial pressure of ammonia in the transferred waste was lower than that over the predilution SY-101 waste. The two causes of decrease were the reduction in the ammonia concentration, directly proportional to the dilution, and the increase in the ammonia solubility that resulted from dilution of the salt.

To approximate the ammonia equilibrium partial pressure over the diluted waste, we use the ammonia measurements made of the SY-101 simulant SY1-SIM-93B, which was similar to SY-101 waste diluted with water at less than a 1:1 ratio (Norton and Pederson 1994). After inline dilution and a slight increase in temperature, the ammonia equilibrium partial pressure is estimated to have been 20,000 to $30,000 \mathrm{ppm} \mathrm{NH}_{3}$ at the $55^{\circ} \mathrm{C}$ transfer temperature. Considering that this waste is mixed with SY-102 waste at lower salt and ammonia concentration and lower temperature, it is possible that the peak ammonia concentration of 7,400 ppm $\mathrm{NH}_{3}$ in the SY-102 headspace approached the ammonia equilibrium partial pressure for the combined waste through which the air bubbled.

The transfers into SY-102 give an example of a disturbance characterized by effective evaporative mass transfer in a highly ventilated tank (about $200 \mathrm{cfm}$ ) containing waste with high dissolved ammonia concentrations and very little retained gas. Figures 3.7 and 3.8 show that, as a result of the high ammonia releases, 400 to 2,000 ppm hydrogen or less would be needed to reach $25 \%$ of the LFL. A ventilation reduction by a factor of between 2 and 10 could hypothetically produce these hydrogen concentrations. The current control limit of 6,250 ppm hydrogen would have been much higher than $25 \%$ of the LFL with the measured ammonia/hydrogen ratio. A considerable decrease in ventilation would have been required for such a high concentration to have been reached with the trivial hydrogen release rate observed in SY-102. Note, though, that if ammonia equilibrium truly was reached in SY-102, the ammonia had already reached the maximum concentration permitted by equilibrium and the measured ammonia/hydrogen ratio would have had to decrease as the hydrogen concentration increased. This would have made the $6,250 \mathrm{ppm}_{2}$ action level more conservative.

The high SY-102 ammonia concentration required a continuing operation to produce the waste disturbance that enhanced ammonia mass transfer. Air sparging (resulting from the vacuum break designed into the drop leg in SY-102) and a free liquid surface were needed for the SY-102 release, and these ended when the transfer did.

We expect it to be typical that near approaches to equilibrium ammonia concentrations will be inconsistent with high hydrogen releases and that they will be easily mitigated by ceasing operations. Near-equilibrium ammonia releases require that there be actively mixed, disturbed liquid. Operations that cause strong disturbances in liquid waste do not typically include thick layers of gas-retaining solids capable of releasing enough retained gas to produce high hydrogen concentrations. 


\subsubsection{U-105 Saltwell Pumping}

Figure 3.9 shows the hydrogen and ammonia concentrations in U-105 before and during the first four months of saltwell pumping, from December 12, 1999 through July 2000. (There was a period between March 6 and April 11, 2000 when no pumping was conducted.) The total flammability was above 5\% of LFL for more than a month and peaked on February 15, 2000 at $6.6 \%$ of LFL. The peak hydrogen concentration, which also occurred on February 15, was 1,650 $\mathrm{ppm}$, at which time the ammonia concentration was $3,400 \mathrm{ppm}$. Ammonia at 3,000 to 3,600 ppm made up about a third of the total flammability during the peak flammability period, so the hydrogen concentration representing $25 \%$ of the LFL was between 5,600 and 6,400 ppm.

The U-105 data show that saltwell pumping can produce total flammabilities that are a significant fraction of the $25 \%$ LFL action level and that ammonia contributes significantly to flammability. However, the 6,250-ppm hydrogen control limit would have conservatively represented $25 \%$ of the LFL during the period of increasing flammability and somewhat beyond.

Assuming that the timing and rates of the U-105 releases are potentially representative of other tanks to be saltwell pumped and of other gradual bubble/evaporation releases in tanks without supernatant layers, is it possible that flammable gas sources or ventilation rates in the other hypothetical situations could lead to much higher total flammabilities? First, other tanks could have lower ventilation rates. In discussing the ventilation rates in SSTs, some mention needs to be made of the fact that passive ventilation rates show some correlation with season. The difference between in-tank and outside temperatures is greater in winter, producing a larger thermal driving force for convection and often increasing the passive ventilation.

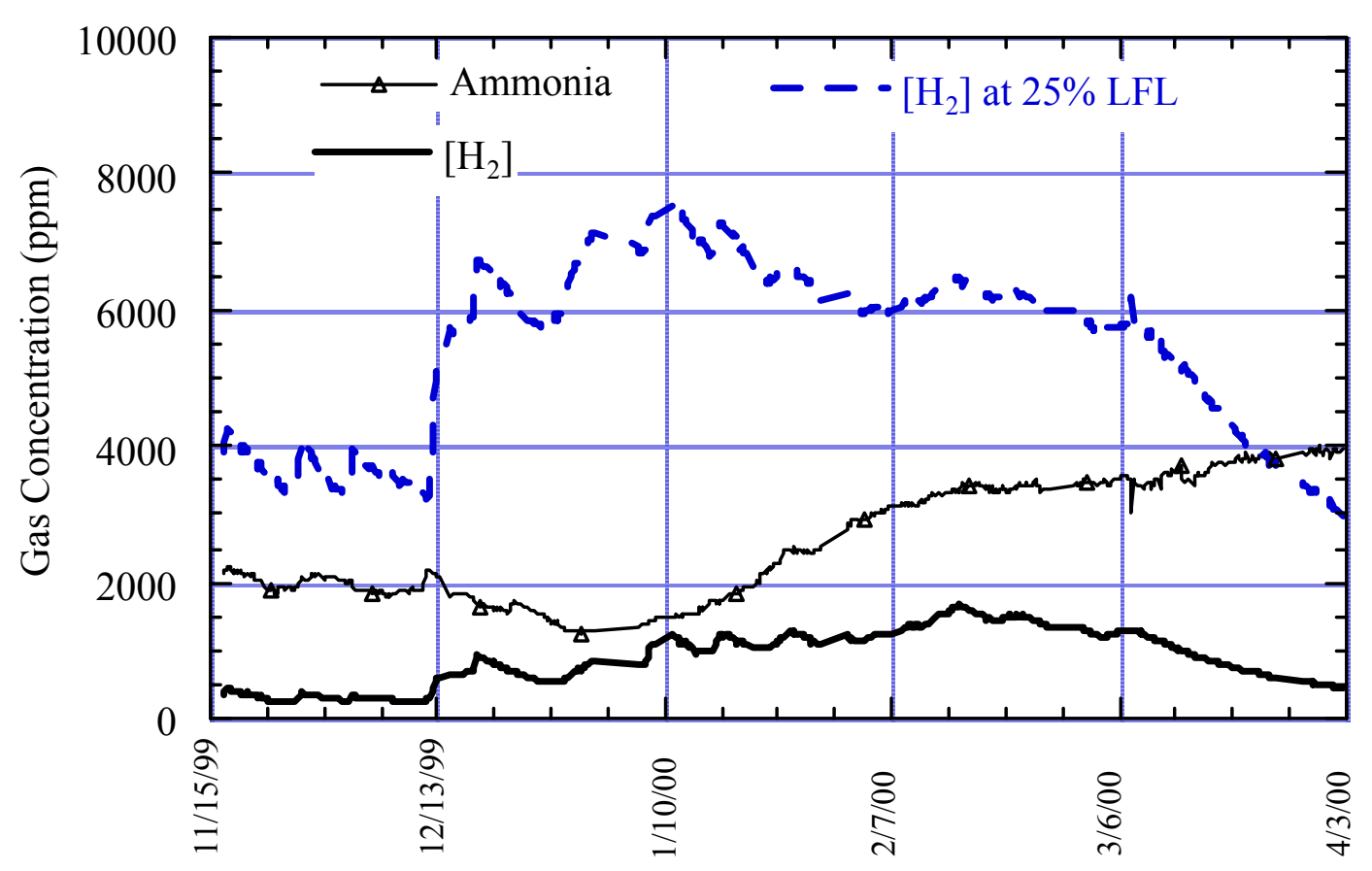

Figure 3.9. Hydrogen and Ammonia in U-105 During Saltwell Pumping 
Huckaby et al. (1997) measured ventilation rates for several SSTs, including U-105, whose ventilation rate was $4 \mathrm{cfm}$. The U-105 ventilation rate was measured in the summer, possibly its low point, while the peak flammability produced by saltwell pumping occurred during winter and early spring, possibly at higher ventilation rates. Those tanks most pertinent to future and ongoing saltwell pumping activities were A-101 (10 cfm, summer), AX-102 (16 cfm, fall), AX-103 (60 cfm, spring), S-102 (2 cfm, fall), and U-103 (1.6 cfm, spring). Based on these data, we cannot rule out the possibility that saltwell pumping could take place in an SST with half the ventilation rate of $\mathrm{U}-105$.

Second, more hydrogen could be present in the retained gas in another tank than in U-105. As noted earlier in this section, it is plausible that hydrogen made up only about $25 \%$ of the retained gas in U-105. In the tanks sampled by RGS (Mahoney 2000), retained gas contained more than $50 \mathrm{vol} \%$ hydrogen twice as often as it contained less than $30 \%$ hydrogen. The amount of total retained gas (and therefore hydrogen) could also have been greater in another tank. The prepumping gas inventory in U-105 was estimated to be $9,500 \mathrm{scfm}$, an in situ gas volume fraction of 0.12. Fewer than half of the SSTs with best-estimate gas volumes had higher gas volume fractions or inventories (Hedengren et al. 2001). Of these, some had higher hydrogen fractions in the retained gas while others were about equal. Considering the effects of both hydrogen fraction and total retained gas, a tank could easily contain twice as much hydrogen as U-105 and might contain even more than that.

Third, a higher ammonia equilibrium partial pressure could be present in a tank waste other than U-105. Grab samples in U-105 contained ammonia concentrations consistent with an equilibrium vapor concentration of $9,000 \mathrm{ppm}$ (as in Table 3.1). Thus, the peak ammonia concentration of $4,000 \mathrm{ppm}$ was about $44 \%$ of the equilibrium value. Table 3.1 shows a number of saltcake SSTs with higher calculated ammonia vapor pressures than U-105. The ammonia equilibrium concentration could be as high as 84,000 ppm, as in AX-101, instead of 9,000 ppm.

Suppose all the factors just discussed were applied at once because all are reasonably probable and experience shows no reason to consider them mutually exclusive. The peak hydrogen concentration would be $6,600 \mathrm{ppm}$ instead of $1,650 \mathrm{ppm}$, and the simultaneous ammonia concentration would be $31,000 \mathrm{ppm}$ instead of $3,400 \mathrm{ppm}$. The total flammability would be $37 \%$ of LFL. The hydrogen concentration when the mixture reached $25 \%$ of LFL would be 4,100 ppm hydrogen. At the estimated maximum ammonia concentration of $36,000 \mathrm{ppm}$, a hydrogen concentration of $6,250 \mathrm{ppm}$ would produce a total headspace flammability of $36 \%$ of the LFL. Although this is greater than $25 \%$ of the actual LFL, the current limit would provide an adequate margin to $100 \%$ of the LFL.

\subsubsection{S-106 Saltwell Pumping}

Figure 3.10 shows the gas concentrations in S-106 during the early phase of saltwell pumping, when flammable gas concentrations in the headspace were highest. Pumping lasted from April 15, 1999 to January 6, 2000. The total flammability peaked near 5\% of LFL, with a maximum hydrogen headspace concentration of 1,920 ppm hydrogen; at that time the ammonia concentration was $100 \mathrm{ppm}$. Ammonia concentrations were negligible in S-106, and the hydrogen concentration for $25 \%$ of LFL was consistently between 9,500 and 10,000 ppm. 


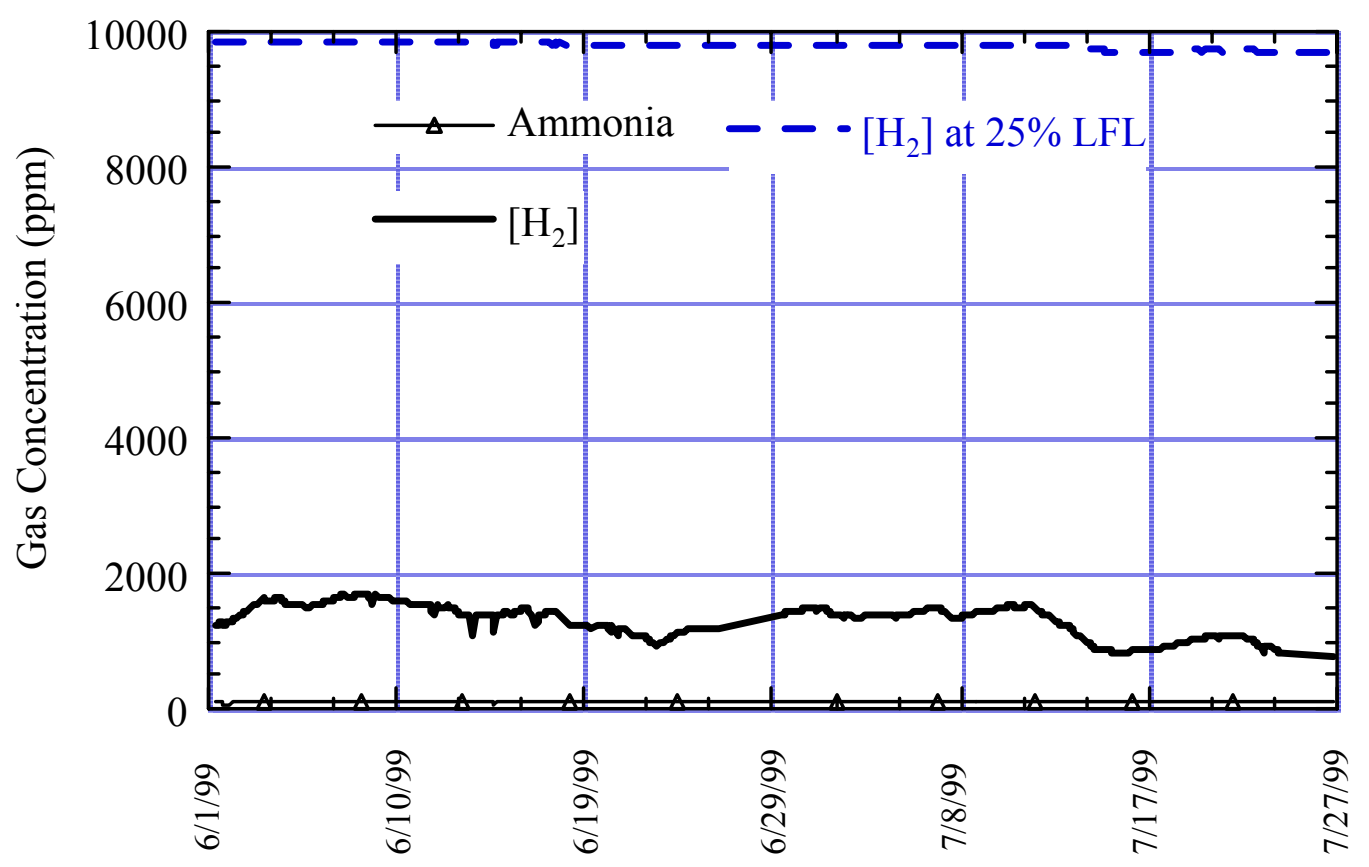

Figure 3.10. Hydrogen and Ammonia in S-106 During Early Saltwell Pumping

Once again we consider whether the $25 \%$ LFL flammability could occur at less than $6,250 \mathrm{ppm}$ hydrogen if the fraction of retained gas in S-106 were released at the same rates in another (hypothetical) tank and if evaporative mass-transfer limitations were the same. S-106 waste contained a larger-than-average total gas inventory, and the gas, at $63 \%$ hydrogen, was among the three highest in hydrogen that were measured by RGS. The tank waste liquid was low in dissolved ammonia, containing at most $200 \mu \mathrm{g} / \mathrm{mL}$ according to grab samples in the TWINS database, or $430 \mu \mathrm{g} / \mathrm{mL}$ according to RGS. Based on the RGS retained gas composition, the ammonia equilibrium partial pressure over S-106 liquid is estimated as equivalent to 3,000 ppm ammonia in the headspace (Table 3.1). Actual ammonia concentrations in the headspace peaked at about $120 \mathrm{ppm}$ ammonia, or $4 \%$ of the equilibrium partial pressure. Evaporative mass transfer was much less effective in S-106 than in U-105 (which reached $40 \%$ of the equilibrium ammonia concentration).

The same gas release fraction and rate as in S-106 probably could not have produced a significantly greater hydrogen release in another tank, considering both the total gas inventory and the hydrogen fraction in S-106. The ventilation rate in S-106 was $9 \mathrm{cfm}$ when measured in spring $1999,{ }^{(a)}$ five times higher than some SSTs, so the concentrations of flammable gases could have been five times as high in another tank. Finally, the low ammonia concentration would have been about 25 times as high if the same evaporative conditions had occurred in a tank with a high ammonia equilibrium partial pressure, such as AX-101.

(a) Peurrung LM and JL Huckaby. March 10, 2000. Gas Release Behavior During Salt-Well Pumping. Letter Report TWS00.39, from J Brothers to GD Johnson (CHG). Pacific Northwest National Laboratory, Richland, WA. 
Extrapolating S-106 gas releases to a hypothetical tank with higher ammonia and lower ventilation along the lines indicated above gives a peak concentration of 9,600 ppm hydrogen and a simultaneous concentration of $13,000 \mathrm{ppm}$ ammonia. These correspond to a flammability of $33 \%$ of the LFL, with 7,350 ppm hydrogen at $25 \%$ of the LFL. A control limit of 6,250 ppm hydrogen would be conservative in this case.

\subsubsection{Saltwell Pumping in S-111}

Saltwell pumping in S-111 was halted in February 2002 when the headspace hydrogen concentration approached $6,000 \mathrm{ppm}$. It eventually peaked at $6,600 \mathrm{ppm}$ a few days later. No ammonia data were available during this time; however, it is useful to consider this event because it was one of the few times that the 6,250-ppm hydrogen control limit actually halted an operation.

Saltwell pumping in S-111 began on December 18, 2001 but was halted on December 21. Pumping restarted on January 30, 2002. The hydrogen concentration quickly rose to 5,700 ppm late on February 7, and saltwell pumping was subsequently shut down. The hydrogen concentration continued to rise and remained above the action level of 6,250 ppm for several more days. It eventually peaked on February 11 at $6,530 \mathrm{ppm}$. The headspace hydrogen concentration from January 31 to February 13, 2002 is plotted in Figure 3.11. The periodic peaks were attributed to the effect of sunlight hitting the electrochemical cells inside the cabinet. The total gas release was estimated to be at least $640 \mathrm{scf}$. That corresponds to about $4 \%$ of the estimated total 14,500 scf of retained gas in S-111 (Hedengren et al. 2001).



Figure 3.11. Hydrogen Concentration During Saltwell Pumping in S-111 
In the absence of ammonia monitoring data, the equilibrium ammonia concentration derived from RGS data can be used as an upper bound to check the flammability of the mixture. Table 3.1 gives an equilibrium ammonia concentration of $1.1 \mathrm{vol} \%(11,000 \mathrm{ppm})$. Combined with the peak hydrogen concentration of $6,500 \mathrm{ppm}$, the mixture flammability is $24 \%$ of the LFL. The hydrogen concentration corresponding to $25 \%$ of the LFL for this mixture is 6,900 ppm, higher than the current action limit. However, because the full equilibrium ammonia concentration is unattainable, a more realistic assumption would be $44 \%$ of the equilibrium concentration, as was estimated for U-105. This would make the ammonia concentration approximately $4,800 \mathrm{ppm}$, which, with $6,500 \mathrm{ppm}$ hydrogen, would yield $19 \%$ of the LFL. In either case, the current limit of $6,250 \mathrm{ppm}$ hydrogen is appropriate.

\subsubsection{Saltwell Pumping in A-101}

Saltwell pumping began in Tank A-101 on May 6, 2000. Only a small volume of waste was pumped before pump problems caused a hiatus in operations, beginning in July 2000. Pumping resumed on January 18, 2002 but shut down between March 13 and April 11. Hydrogen concentrations remained at $600 \mathrm{ppm}$ or less through this period, and ammonia data were unavailable. On April 17, shortly after pumping restarted, hydrogen spiked to $1500 \mathrm{ppm}$. Pumping was sporadic between this date and May 28, when another hiatus occurred that lasted though July 20.

At the time pumping restarted, the headspace hydrogen was low (100 to $300 \mathrm{ppm}$ ) and ammonia was about 1,200 ppm, as shown in Figure 3.12. Both had been gradually decreasing. On the day pumping resumed, both gases began to increase in concentration. Over the course of

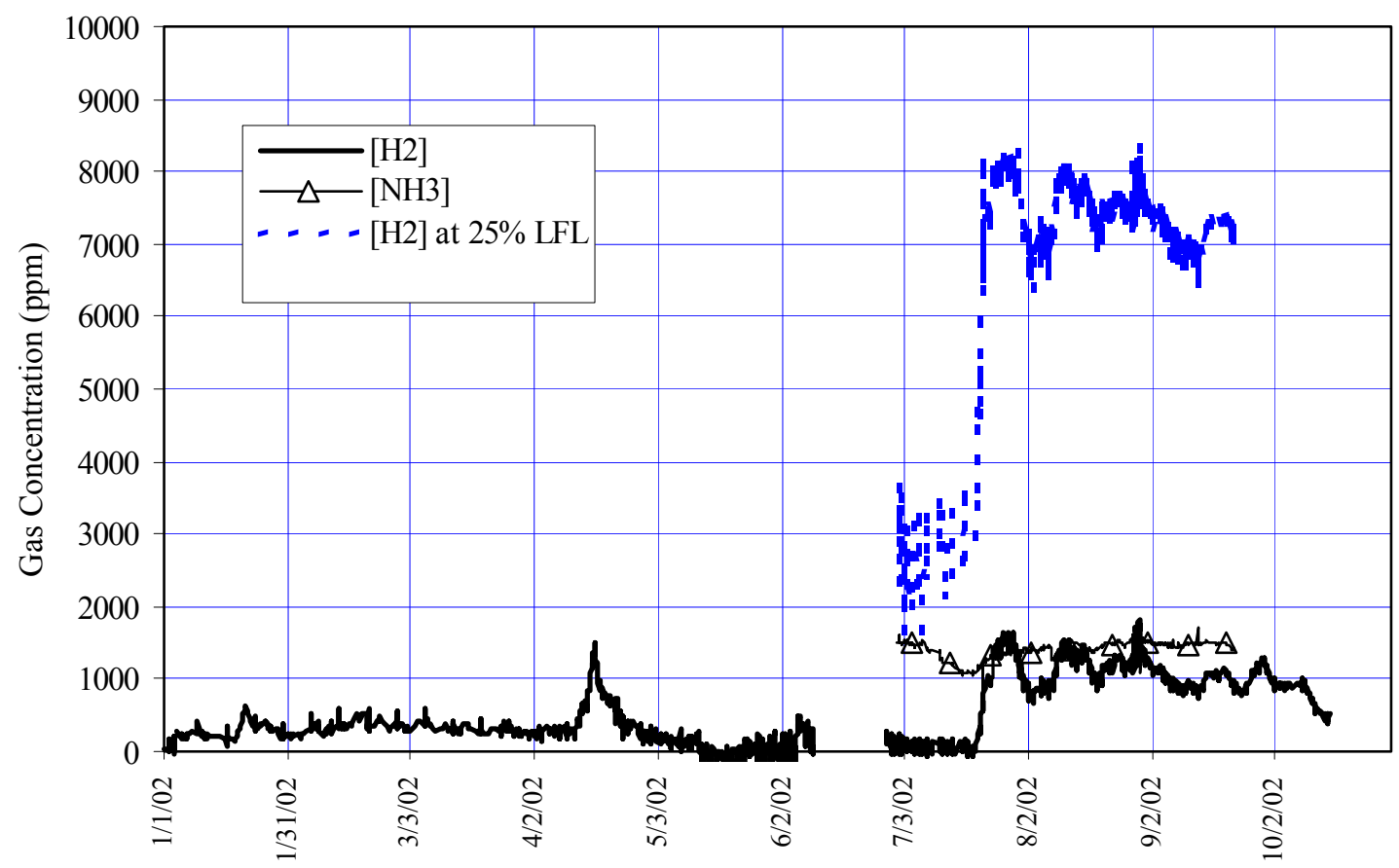

Figure 3.12. Hydrogen and Ammonia in A-101 During Saltwell Pumping 
six days, hydrogen rose to $1600 \mathrm{ppm}$ and ammonia to $1360 \mathrm{ppm}$. The hydrogen peak to date was on August 30,1,800 ppm of hydrogen with a simultaneous ammonia measurement of 1,500 ppm (about $4 \%$ of the equilibrium ammonia concentration of $35,000 \mathrm{ppm}$, per Table 3.1). The hydrogen at $25 \%$ of LFL varied between 6,500 and 8,000 ppm during this period, greater than the current action limit.

The same gas release fraction and rate as A-101 probably could not have produced a significantly greater hydrogen release in another tank, considering both the large total gas inventory and the high hydrogen fraction in A-101. The ventilation rate in A-101 was $10 \mathrm{cfm}$ when measured in summer, five times higher than some SSTs, so the concentrations of flammable gases could have been five times as high in another tank. The dissolved ammonia concentration is moderately high in A-101; as shown in Table 3.1, the highest equilibrium ammonia vapor pressure, estimated at 84,000 ppm in AX-101, is about 2.5 times that in A-101.

In the extrapolated case, the peak hydrogen would be five times as high as in A-101, or $9,000 \mathrm{ppm}$, and the simultaneous ammonia would be $19,000 \mathrm{ppm}$. This would produce a flammability of $35 \%$ of the LFL. At $25 \%$ of the LFL, the hydrogen would be 6,400 ppm, higher than the current action limit.

Tank AX-101, whose waste is similar to that in A-101, is also undergoing saltwell pumping at the time of this report. However, the hydrogen measurements show considerable scatter and there is no ammonia instrument on the tank. Hence AX-101 is not further considered in this report.

\subsection{Theoretical Modeling of Ammonia Releases}

Several models have been used at Hanford to predict ammonia releases and mass transfer from several types of releases and events. The list, which is intended to touch upon the modeling history rather than to be comprehensive, includes the following:

- Palmer et al. (1996) and Terrones et al. (1997), who modeled ammonia transfer through the crust, supernatant, and settled solid layers of waste in an undisturbed tank based on RGS data.

- Mahoney et al., who modeled the release of ammonia from a bubble slurry flow "erupting" through the crust in SY-101 during waste transfer and dilution. ${ }^{\text {(a) }}$

- Hedengren et al. (2000b), who modeled ammonia release into the headspace from a waste falling freely through the headspace and from the disturbed and stagnant areas of the liquid surface in a double-contained receiver tank (DCRT).

These models typically predict higher ammonia concentrations and closer approaches to equilibrium than are borne out by the few observations. For example, Mahoney et al. predicted peak ammonia concentrations of $6,400 \mathrm{ppm}$ (less than $10 \%$ of the equilibrium partial pressure) in

(a) Mahoney LA, PA Meyer, and CW Stewart. 1999. Ammonia Release from Bubble Slurry Flow Through a Hole in the Crust Layer in SY-101. TWS99.35, PNNL, Richland, WA. 
the SY-101 headspace. ${ }^{(a)}$ Actual measurements peaked at 720 ppm ammonia (less than $1 \%$ of equilibrium). As another example, Hedengren modeled ammonia releases in SY-102 resulting from the SY-101 waste transfer. ${ }^{(b)}$ The model (similar to the one described by Hedengren et al. [2000b]) predicted a peak ammonia concentration of 22,300 ppm ammonia in SY-102 (69\% of the ammonia equilibrium partial pressure used by that model), even without including the aggravating effect of inadvertent air sparging. The highest concentration actually observed was $7,400 \mathrm{ppm}$ ammonia, which was probably between 50 and $100 \%$ of the actual equilibrium partial pressure.

The general overestimation of the ammonia partial pressure by theoretical models may result from conservatism in estimating the ventilation rate, the ammonia equilibrium partial pressure, evaporative mass-transfer coefficient, mass-transfer area, or ammonia inventory available for release. Our intent in using historical events as starting points for extrapolation was to take an approach that supplemented theoretical ammonia modeling by removing the mass-transferrelated conservatisms, retaining only that involved in estimating the ammonia equilibrium partial pressure.

(a) Mahoney LA, PA Meyer, and CW Stewart. 1999. Ammonia Release from Bubble Slurry Flow Through a Hole in the Crust Layer in SY-101. TWS99.35, PNNL, Richland, WA.

(b) Hedengren DC. March 11, 1999. Ammonia Concentrations from the Transfer of Waste from Tank SY-101 to Tank SY-102. Letter report 74B0-99-045 to NW Kirch, CHG, Richland, WA. 


\subsection{Conclusions}

The conservatism inherent in the current control limit of 6,250 ppm hydrogen has been established and can be quantified. If no ammonia is present, $6,250 \mathrm{ppm}$ hydrogen is equivalent to $16 \%$ of the LFL. With 6,250 ppm hydrogen present, 12.7 vol\% (126,600 ppm) ammonia is required for the mixture to reach $100 \%$ of the LFL, but the maximum possible ammonia concentration in tanks sampled by the RGS is about $84,000 \mathrm{ppm}$. It takes $14,060 \mathrm{ppm}$ ammonia for $25 \%$ of the LFL, but the highest ammonia concentration actually measured in a tank headspace was $7,400 \mathrm{ppm}$. The presence of water vapor in the tank headspace would further reduce the effect of ammonia.

The large majority of the data and observations show that a higher control limit could be used to represent $25 \%$ of the mixture LFL. However, there are a few cases in which the current control limit is only just adequate or even slightly nonconservative. We have examined the concentrations of flammable gases that were predicted by theoretical models and that resulted from several historical operations in Hanford waste storage tanks. In addition, we have extrapolated several of these observations to the limits of the observed "population" of hydrogen inventories and ammonia equilibrium partial pressures, based on the available measurements.

We believe the analyses and operations we have examined (and extrapolated) represent the range of waste disturbances that could result from future authorized operations in SSTs and DSTs and probably represent conditions that might occur in DCRTs and other tanks that store similar kinds of wastes. We believe they form a reasonable technical basis for evaluating the current control limit. The list includes the following:

- Background release with barometric breathing - this analysis represents DSTs with active ventilation shut down, SSTs during very adverse passive ventilation conditions, and other underground waste storage tanks without active ventilation (see Section 3.2).

- BDGREs in SY-101 - these events represent any large-scale spontaneous bubble releases of retained gas with little contribution from evaporative releases. Such releases could result from activities such as waste removal from DSTs, waste addition to DSTs, mixing sediment in any tank, airlift circulator operation in DSTs, and chemical addition in DSTs (see Section 3.3.1).

- Releases in SY-101 during dilution - these events represent smaller-scale spontaneous bubble releases with evaporation inhibited by a water dilution. This type of release occurred when the thick crust layer was dissolving in SY-101, but similar events on a smaller scale might occur when crust layers in the other DSTs are dissolved during retrieval (see Section 3.3.2).

- Waste transfer into SY-102 - in this event, the primary release was from evaporation of the added waste, strongly aided by what was, in effect, air sparging of the waste inflow. The elevated releases were seen only as long as inflow and sparging continued. Such releases could occur in future transfers into DSTs as a result of similar bubble sparging during airlift circulator operation and might represent transfers into DCRTs (see Section 3.3.3). 
- Saltwell pumping from U-105, S-106, S-111, and A-101-releases from the drainage of liquid in the waste matrix were semi-spontaneous after a certain amount of liquid had been drained and included both bubble and evaporative releases. These releases result from saltwell pumping and possibly saltcake dissolution operations in SSTs (see Sections 3.3.4, 3.3.5, and 3.3.6).

The steady-state flammability analyses with barometric breathing indicated that, in the absence of a mechanism to stir the waste and prevent surface depletion, ammonia concentrations remain low, and the $6,250 \mathrm{ppm}$ hydrogen control limit provided an adequate or conservative representation of $25 \%$ of the mixture LFL in almost $95 \%$ of the tanks considered (all SSTs and DSTs). The maximum was just under $30 \%$ of the LFL. This would support continued use of the current control limit but would not justify a higher one.

In events dominated by bubble release, as in the SY-101 BDGREs and bubble slurry flows and S-106 saltwell pumping, headspace ammonia concentrations were typically much less than $10 \mathrm{vol} \%$ of the estimated ammonia equilibrium concentration, not much higher than what would be expected from retained gas alone without evaporation. In such situations, the existing control limit of 6,250 ppm hydrogen is conservative, and a higher control limit of 7,000 to $8,000 \mathrm{ppm}$ hydrogen could be supported.

The historical operations that involved effective evaporation indicate a more constrained conclusion. In the SY-101 waste transfer into SY-102, the headspace ammonia concentration was 50 to $100 \%$ of the equilibrium partial pressure. For such evaporation-dominated releases, the upper limit on the ammonia concentration remains below the LFL, whether the source of the limit is the ammonia equilibrium partial pressure or mass-transfer/ventilation constraints. In any case, such releases do not support a control limit expressed only in terms of hydrogen.

However, this conclusion is ameliorated by three points, at least for high-volume waste transfers into DSTs represented by transfers of SY-101 waste into SY-102. First, existing waste in the receiver tank is unlikely to be as concentrated as that in SY-102 after receiving highammonia waste from SY-101. Second, the hydrogen is very unlikely to reach $6,250 \mathrm{ppm}$ in a tank receiving a transfer as long as hydrogen is transferred only in dissolved form and the ventilation is near the normal rate. Third, high concentrations of ammonia and hydrogen both require continual transfer and decrease sharply upon operator response to reaching the control limit. Therefore, while a control limit of $6,250 \mathrm{ppm}$ hydrogen could exceed $25 \%$ of the LFL if reached, the mixture could not reach the LFL at this level, and because there is no mechanism for significant hydrogen release during transfer, it would be very unlikely for the hydrogen concentration to approach the limit in the first place.

U-105 saltwell pumping represents all drainage operations where evaporation is effective and the dissolved ammonia concentration is significant (in contrast to the minor ammonia evaporation in S-106 and A-101). Based on reasonable extrapolation from U-105 data, we expect coincident headspace concentrations in such operations to remain below $36,000 \mathrm{ppm}$ ammonia. Both S-111 and BY-106 exceeded 6,250 ppm hydrogen during saltwell pumping (McCain 2001), so elevated hydrogen concentrations could be expected. With 6,250 ppm hydrogen and 36,000 ppm ammonia, the mixture would be at $40 \%$ of the LFL. A hydrogen 
concentration of $3,900 \mathrm{ppm}$ would represent $25 \%$ of the LFL. The gas mixture would not approach the LFL at the existing control limit of 6,250 ppm hydrogen because this would require the ammonia concentrations exceeding the highest equilibrium value estimated for tanks with measurements of dissolved ammonia. Nevertheless, this scenario does not support a control limit higher than the current level.

In summary, the available measurements, analysis results, and observations of historical gas releases show the following:

- The 6,250 ppm hydrogen control limit is very conservative with respect to $25 \%$ of the actual LFL in the majority of conditions and tanks. This includes operations and events dominated by retained bubble releases that result in the highest hydrogen concentrations and flammability levels.

- In some cases where ammonia evaporation is significant, a mixture containing 6,250 ppm hydrogen exceeds $25 \%$ of LFL. However it remained at or below $40 \%$ of LFL in the scenarios considered and could not approach $100 \%$ of LFL even when extrapolated to the highest measured ammonia concentrations. (However, we caution that tanks whose ammonia concentrations have not been measured, notably several of the SX tanks, could conceivably have higher equilibrium ammonia partial pressures.)

- There is neither need nor sound technical basis to recommend a higher hydrogen control limit.

Based on these conclusions, we recommend that the current 6,250 ppm hydrogen control limit continue to be used for operations in Hanford tank farms. 


\subsection{References}

CHG. 2000a. Tank Waste Remediation System Final Safety Analysis Report. HNF-SD-WMSAR-067 Rev. 2, CH2MHILL Hanford Group, Inc., Richland, WA.

CHG. 2000b. Tank Waste Remediation System Technical Safety Requirements. HNF-SD-WMTSR-006 Rev. 2, CH2MHILL Hanford Group, Inc., Richland, WA.

DeCoursey WJ, N Zubryckyj, and N Yoshida. 1962. "Effects of Water Vapor Content on the Inflammable Limits of Ammonia-Oxygen-Nitrogen Mixtures.” Can. J. Chem. Eng. pp. 203-209.

Estey SD. 1998. Flammable Gas Tank Safety Program: Technical Basis for Gas Analysis and Monitoring. HNF-SD-WM-ES-346 Rev. 1, Lockheed Martin Hanford Corp., Richland, WA.

Fenton DL, AS Khan, RD Kelley, and KS Chapman. 1995. "Combustion Characteristics Review of Ammonia-Air Mixtures.” ASHRAE Transactions pp. 476-485.

Gauglitz PA, SD Rassat, PR Bredt, JH Konynenbelt, SM Tingey, and DP Mendoza. 1996. Mechanisms of Gas Bubble Retention and Release: Results for Hanford Waste Tanks 241-S-102 and 241-SY-103 and Single-Shell Tank Simulants. PNNL-11298, Pacific Northwest National Laboratory, Richland, WA.

Hedengren DC, KM Hodgson, WB Barton, CW Stewart, JM Cuta, and BE Wells. 2000a. Data Observations on Double-Shell Flammable Gas Watch List Tank Behavior. RPP-6655 Rev. 0, CH2MHILL Hanford Group, Inc., Richland, WA.

Hedengren DC, SA Barker, RJ Hendershot, JD Bingham, and MA Kufahl. 2000b. Methodology for Predicting Flammable Gas Mixtures in Double-Contained Receiver Tanks. RPP-4941 Rev. 0-B, CH2MHILL Hanford Group, Inc., Richland, WA.

Hedengren DC, TA Hu, MA Kufahl, DJ McCain, CW Stewart, JL Huckaby, LA Mahoney, and KG Rappe. 2001. Data and Observations of Single-Shell Flammable Gas Watch List Tank Behavior. RPP-7249 Rev. 0, CH2MHILL Hanford Group, Inc., Richland, WA.

$\mathrm{Hu}$ TA, SA Barker, DC Hedengren, and MA Kufahl. 2002. Steady-State Flammable Gas Release Rate Calculation and Lower-Flammability Level Evaluation for Hanford Tank Waste. RPP-5926 Rev. 2, CH2MHILL Hanford Group, Inc., Richland, WA.

Huckaby JL, JC Evans, DS Sklarew and AV Mitroshkov. 1998. Waste Tank Ventilation Rates Measured with a Tracer Gas Method. PNNL-11925, Pacific Northwest National Laboratory, Richland, WA.

Johnson GD, DC Hedengren, JM Grigsby, CW Stewart, JJ Zach, and LM Stock. 2001. Flammable Gas Safety Issue Resolution. RPP-7771 Rev. 0-A, CH2MHILL Hanford Group, Inc., Richland, WA.

Khan AS, RD Kelley, KS Chapman, and DL Fenton. 1995. "Flammability Limits of AmmoniaAir Mixtures." ASHRAE Transactions pp. 454-461.

Mahoney LA, ZI Antoniak, JM Bates, and ME Dahl. 1999. Retained Gas Sampling Results for the Flammable Gas Program. PNNL-13000, Pacific Northwest National Laboratory, Richland, WA. 
Mahoney LA. 2000. Ammonia Results Review for Retained Gas Sampling. PNNL-13317, Pacific Northwest National Laboratory, Richland, WA.

Mahoney LA, JL Huckaby, SA Bryan, and GD Johnson. 2000a. Overview of the Flammability of Gases Generated in Hanford Waste Tanks. PNNL-13269, Pacific Northwest National Laboratory, Richland, WA.

Mahoney LA, ZI Antoniak, WB Barton, JM Conner, NW Kirch, CW Stewart, and BE Wells. 2000b. Results of Waste Transfer and Back-Dilution in Tanks 241-SY-101 and 241-SY-102. PNNL-13267, Pacific Northwest National Laboratory, Richland, WA.

McCain DJ. 2001. Results of Vapor Space Monitoring of Flammable Gas Watch List Tanks. HNF-SD-WM-TI-797 Rev. 6, CH2MHILL Hanford Group, Inc., Richland, WA.

Meyer PA, ME Brewster, SA Bryan, G Chen, LR Pederson, CW Stewart, and G Terrones. 1997. Gas Retention and Release Behavior in Hanford Double-Shell Waste Tanks. PNNL-11536 Rev. 1, Pacific Northwest National Laboratory, Richland, WA.

Meyer PA and CW Stewart. 2001. Preventing Buoyant Displacement Gas Release Events in Hanford Double-Shell Waste Tanks. PNNL-13337, Pacific Northwest National Laboratory, Richland, WA.

NFPA. 1969. Explosion Prevention Systems. National Fire Protection Association, Quincy, MA.

Norton JD and LR Pederson. 1994. Ammonia in Simulated Hanford Double-Shell Tank Wastes: Solubility and Effects on Surface Tension. PNL-10173, Pacific Northwest National Laboratory, Richland, WA.

Palmer BJ, JM Cuta, JM Anderson, TA Ferryman, G Chen, and G Terrones. 1996. Evaluation of the Potential for Significant Ammonia Releases from Hanford Waste Tanks. PNNL-11237, Pacific Northwest National Laboratory, Richland, WA.

Shekarriz A, DR Rector, LA Mahoney, MA Chieda, JM Bates, RE Bauer, NS Cannon, BE Hey, CG Linschooten, FJ Reitz, and ER Siciliano. 1997. Composition and Quantities of Retained Gas Measured in Hanford Waste Tanks 241-AW-101, A-101, AN-104 and AN-103. PNNL11450, Pacific Northwest National Laboratory, Richland, WA.

Stewart CW, Meyer PA, ME Brewster, KP Recknagle, PA Gauglitz, HC Reid, and LA Mahoney. 1996. Gas Retention and Release Behavior in Hanford Single-Shell Waste Tanks. PNNL11391, Pacific Northwest National Laboratory, Richland, WA.

Stewart CW, Meyer PA, and JL Huckaby. 2002. Effects of Globally Waste Disturbing Activities on Gas Generation, Retention, and Release in Hanford Waste Tanks. PNNL-13781, Pacific Northwest National Laboratory, Richland, WA.

Stock LM. 2000. The Chemistry of Flammable Gas. RPP-6664 Rev. 0, CH2MHILL Hanford Group, Inc., Richland, WA.

Terrones G, BJ Palmer, and JM Cuta. 1997. Ammonia Concentration Modeling Based on RGS Data. PNNL-11674, Pacific Northwest National Laboratory, Richland, WA. 
Wells BE, JM Cuta, SA Hartley, LA Mahoney, PA Meyer, and CW Stewart. 2002. Analysis of Induced Gas Releases During Retrieval of Hanford Double-Shell Tank Waste. PNNL-13782, Pacific Northwest National Laboratory, Richland, WA. 


\section{Distribution}

No. of

Copies

Offsite

H. Babad

2540 Cordoba $\mathrm{Ct}$.

Richland, WA 99352-1609

\section{Onsite}

6 DOE Office of River Protection

CA Groendyke (5)

DH Irby

$16 \underline{\text { CH2MHILL Hanford Group }}$

SA Barker

WB Barton

CA Carro

WL Cowley (5)

JM Grigsby
No. of

Copies

DC Hedengren

R2-11

TA Hu

R2-11

NW Kirch

$\mathrm{R} 2-11$

LJ Kripps

R1-44

DA Reynolds

R2-11

CHG Correspondence Control

H6-08

TCSRC

18 Pacific Northwest National Laboratory

H6-60

SQ Bennett

K7-90

H6-60

JW Brothers (3)

$\mathrm{K} 7-15$

JL Huckaby

$\mathrm{K} 7-15$

WL Kuhn

$\mathrm{K} 7-15$

LA Mahoney (6)

K7-15

R2-11

CW Stewart

$\mathrm{K} 7-15$

R2-11

G Terrones

K7-15

R1-44

BE Wells

K7-15

R1-44

J Young

K7-97

R1-44

K1-06 